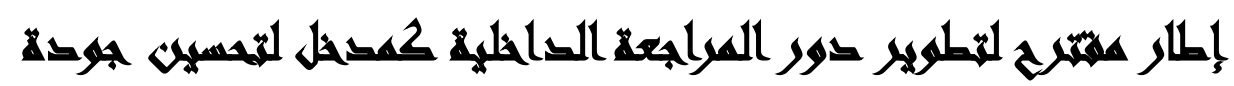

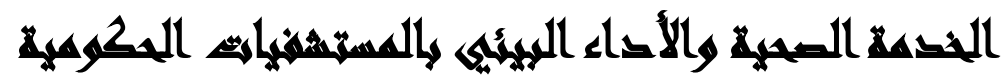

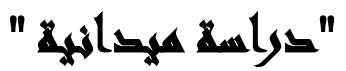

[11]

محمد عبد الفتاح محمد(') - محمد عزمي محمد خفاجي(Y) (Y) - أحمد عبد الحميد قزامل

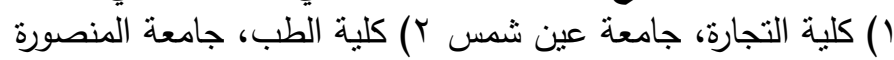

\section{المستخله دو}

هدفت الدراسة إلي وضع إطار مقترح لتطوير دور المراجع الداخلي في تحسين جودة

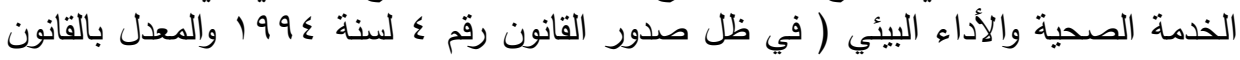

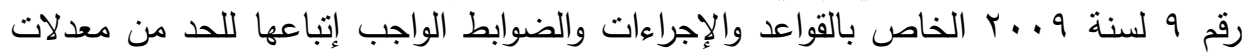

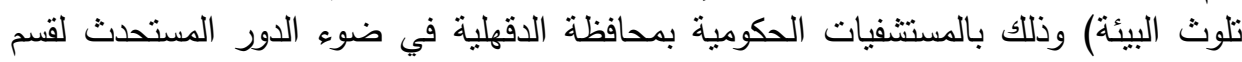

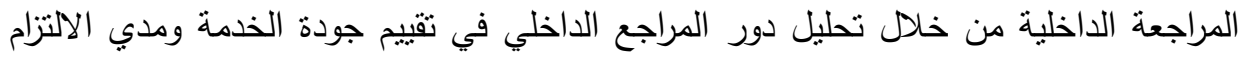

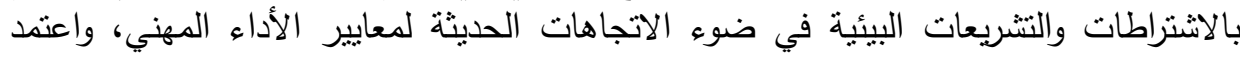

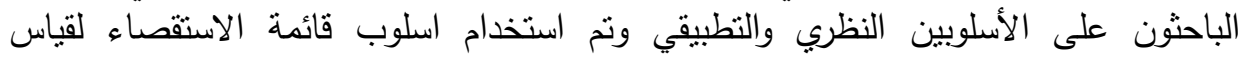

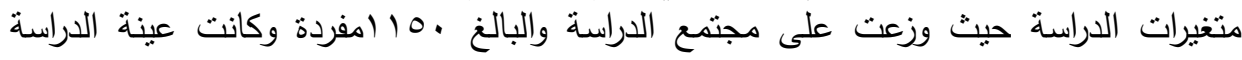

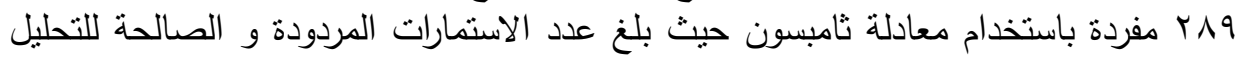

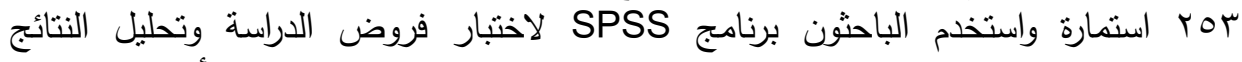
وتوصلت الدراسة إلي وجود علاقة ارتباط طردي قون بارن بين المراجعة الداخلية بأبعادها (تطبيق

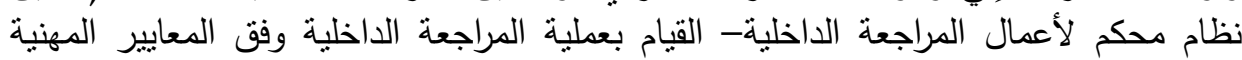

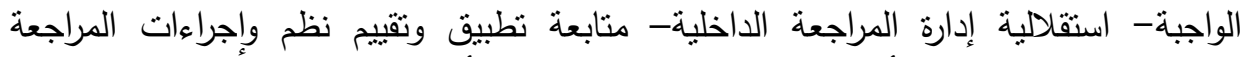

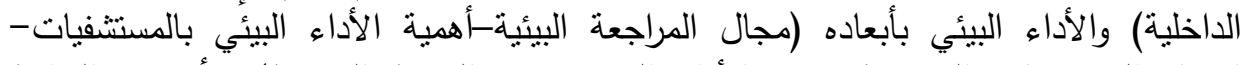

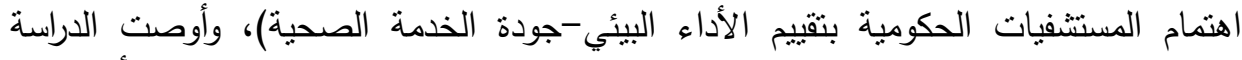

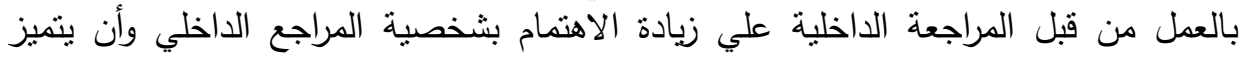

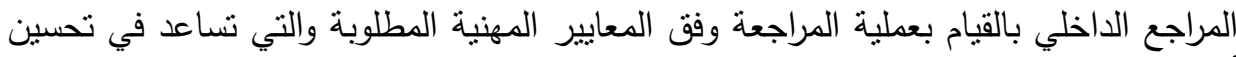

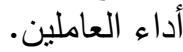




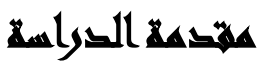

تؤدي المنظمات الخدمية دوراً هاماً في اقتصاديات الدول المختلفة حيث نتزايد درجة تعقد

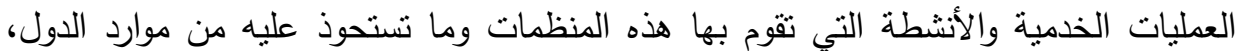
ومن هنا تبرز الحاجة الملحة لمراجعة أنشطة هذه المنظمات وبرمجة عملياتها للتحقق من كفاءة

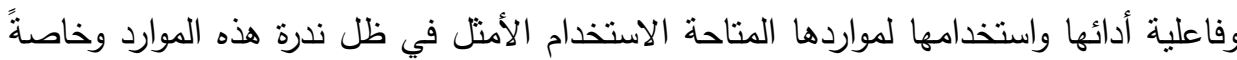
في دول العالم الثالث.

وعلى الرغم من أن مراجعة الوحدات الحكومية وبخاصة الخدمية منها و التي ارتبطت تطبيقاتها بظهور الدول والحكومات إلا أن تطورها تم ببطء شديد بالدقارنة بالتطورات التي حدثت

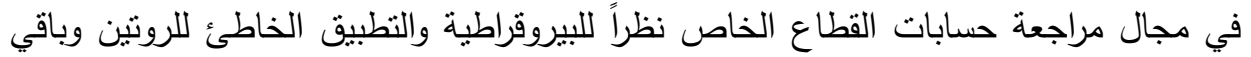
المعوقات التي أصابت القطاع الحكومي ككل والتي لا يقبلها القطاع الخاص(مصطفي محمد

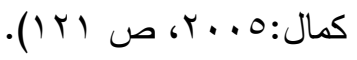
أما في عصر الاستراتيجيات التتافسية التي تهدف إلى تحقيق أعلى مستوى جودة للخدمات

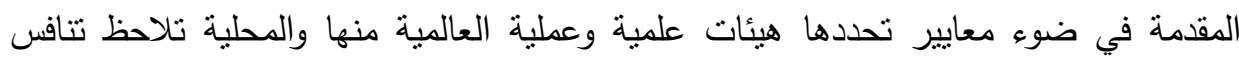
المنظمات في تقديم خدمات ذات جودة عالية تراعي الاثتراطات والتشريعات البيئية لكي تحوز

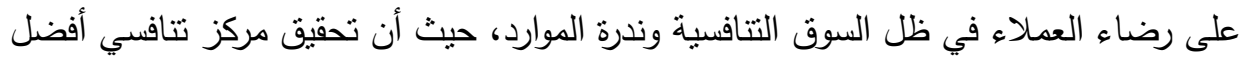
ينوقف على جودة الخدمات المؤداة، ولكي يتحقق ذلك تحتاج المنظمة إلى تطبيق مبادئ للجودة في أنشطتها المختلفة، كما أنه في إطار حرص الدولة علي المحافظة على مكونات البيئة ومنع تلوثها وتقليل حدة التلوث التي قد تؤدي بطريق مباشر أو غير مباشر إلي الإضرار بصحة

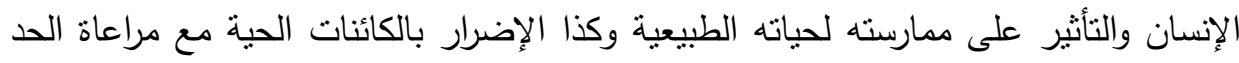

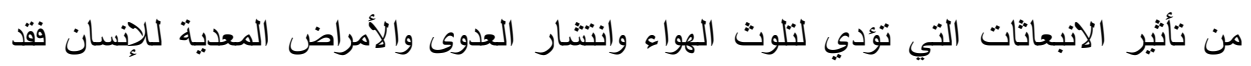

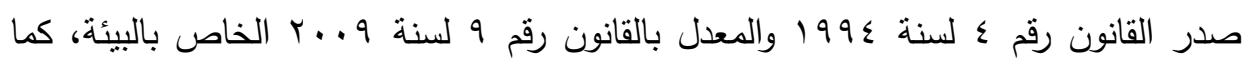
صدرت اللائحة التنفيذية للقانون بموجب قرار رئيس مجلس الوزراء رقم ربr لسنة 1990 


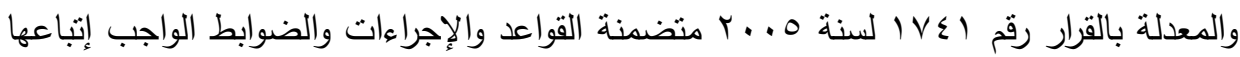
للحد من معدلات نلوث البيئة.

وتتحقق جودة الخدمة والأداء البيئي من خلال تكامل وتفاعل جميع وحدات المنظمة في تأدية أعمالها بأفضل الطرق للنهوض بمستوى الأداء والذي يضمن الاستخدام الأمتل للموارد

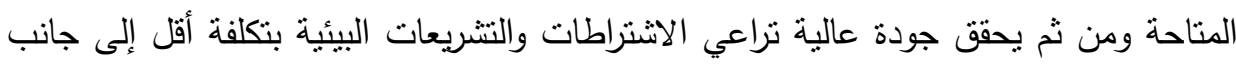
رضاء العملاء. ولتأكيد تحقيق جودة الخدمة والأداء البيئي تحتاج المنظمة إلى جهة مستقلة عن أقسامها

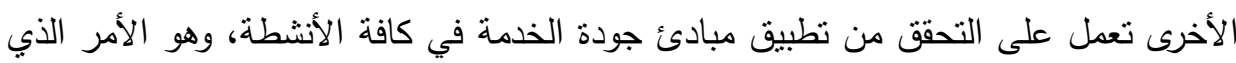

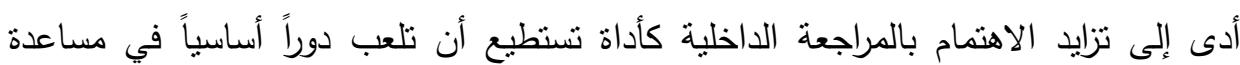
الإدارة على التحقق من تطبيق مبادئ جودة الخدمة.

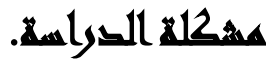

مع انضمام مصر لمنظمة التجارة العالمية World Trade Organization وتحرير تجارة السلع والخدمات طبقا لما شملته الاتفاقيات التي تضمنتها الوثيقة الختامية لجولة أورجواي ( 1919 - 1994 ) وجداول التعهدات التي وقعت عليها الدول الأعضاء في المنظمات اثتعلت حدة المنافسة بين هذه الدول مما زاد الطلب على جودة السلع والخدمات خاصة مع السعي الدؤوب من قبل المنظمات المختلفة للحصول على شهادات الجودة الصناعية والخدمية والبيئية في ظل ظهور العديد من القوانين التي تدعم اتجاهات المحافظة على البيئة وحماية العميل، وترغب في الارتقاء بمستوى الخدمة المؤداة ومن ثم تزايد تكاليف عدم الالتزام بنلك لكائ القوانين.

ونتيجة لنزايد تلك الضغوط كان لابد من وجود أدوات للرقابة على أداء المنظمات للوفاء بتلك الالتزامات الجديدة التي فرضتها التطورات الاقتصادية والسياسية والاجتماعبة والبيئية العالمية منها والمحلية، وهو ما استلزم من الإدارة العليا مواكبة هذه التطورات بحيث أصبحت الإدارة في حاجة ملحة إلى معلومات موثوق بها عن كافة النواحي المالية والتتغيلية والبيئية بما

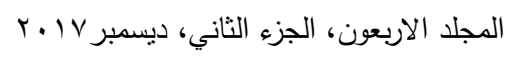


يساعدها في التحقق من صحة التزام المنظمة بجميع أقسامها بالاستخدام الأمثل والفعال للموارد

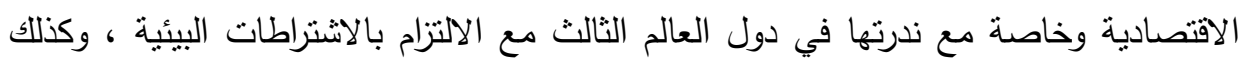

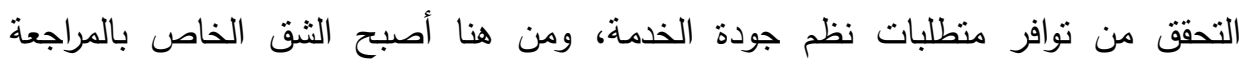
والمراجعين الداخليين من أهم المكونات في نظم المراجعة الحديثة حيث ذاد الاهنمام بهذا الثق بنق

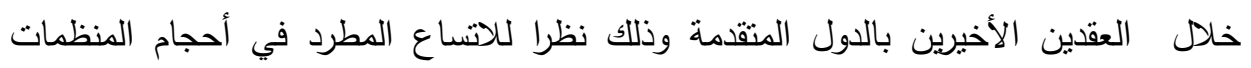
وكثافة العمليات المالية والإدارية والرقابية المصاحبة لذلك والمطلوب مراجعتها أولا بأول في

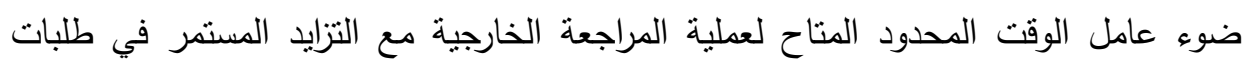

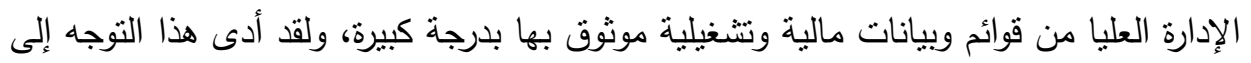

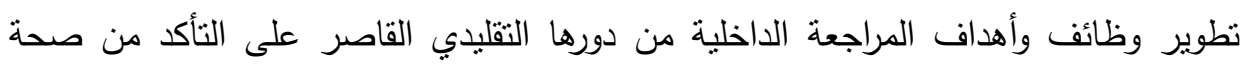

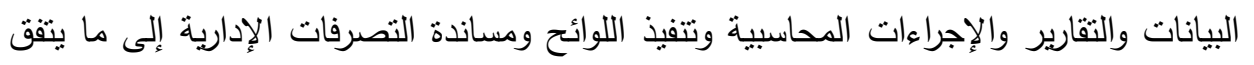
مع مبادئ جودة الخدمة وبذلك أصبحت الإدارة تتظر إلى وظيفة المراجعة الداخلية على أنها أداة مساعدة على تطبيق فلسفة جودة الخدمة في ظل الالتزام بالاشتراطات والتتريعات البيئية، ومن الته ثم الارتقاء بمستوى الأداء بالثكل الذي يساعد الإدارة على تحقيق رضاء العملاء وتقديم خدمات تنافسية وبالتالي خلق فرص التحسين والتطوير والمشاركة الفعالة في التخطبط والتتفيذ لهذه الخطط من خلال فرق العمل بالمنظمة.

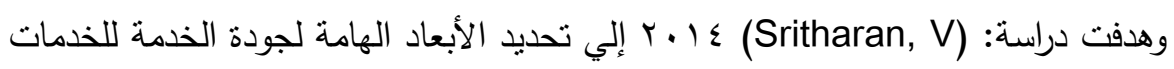
المقدمة بمعرفة المستشفيات الخاصة، ومحاولة فهم العوامل المؤثرة في جودة الخدمة بالمستتفيات الخاصة، واعتمد الباحثون علي مقياس SERVQUAL لقياس جودة الخدمة

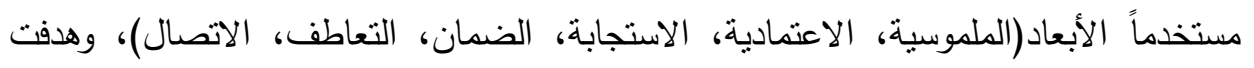

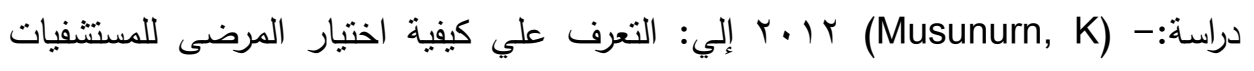
بالنسبة لمعايير معينة، والتعرف علي ايجابيات وسلبيات الخدمة الصحية من وجهة نظر المريض، والتعرف علي توقعات المريض الإضافية من مقدم الخدمة الصحية، وتم جمع بيانات الدراسة الأولية من خلال عينة قوامها بو مريضاً بمدينة حيدر أباد بالهند. 
في حين هدفت دراسة: طلا الدغمي • ا.ب إلي: التعرف علي مستوي جودة خدمات الرعاية الصحية التي يقدمها مستشفى قوي الأمن من وجهة نظر المستفيدين، والتعرف علي

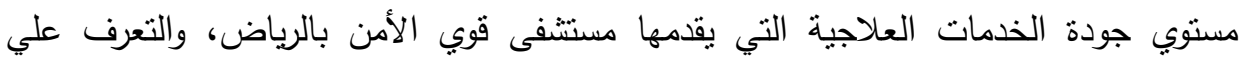

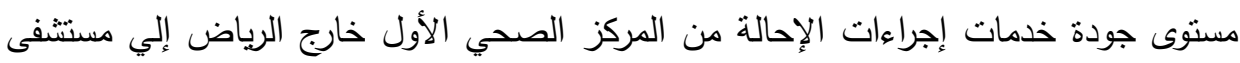

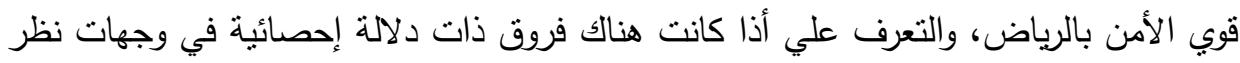
المستقيدين من جودة الخدمة الصحية حول محاور الدراسة وفقا لمتغيرات الثخصية، كما أظهرت الدراسة الاسنطلاعية التي قام بها الباحثون والتى تمت بمقابلت ه مجموعات من

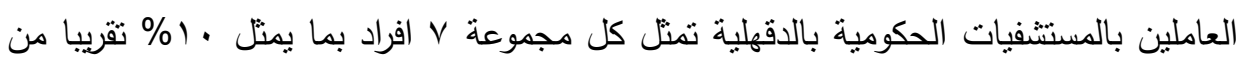

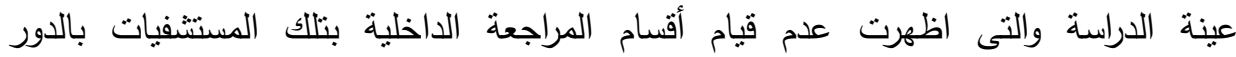

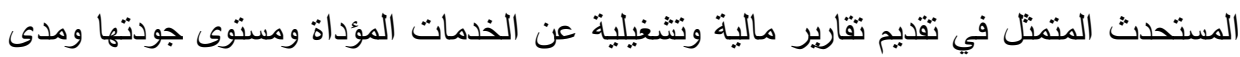

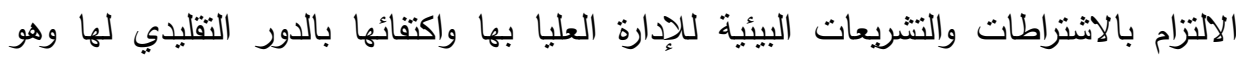
مراجعة مستتدات الصرف فقط. حيث قام الباحثون بإجراء دراسة استطلاعية وذلك لتوفير البيانات الأولية التى سوف يتم استخدامها وتحليلها لأغراض اختبار الفروض والتي تعد الأساس في الوصول دراسل إلى نتى نتائج وتوصيات الدراسة، وتتمتل هذه البيانات في استجابات مفردات عينة الدراسة، وذلك من خلال

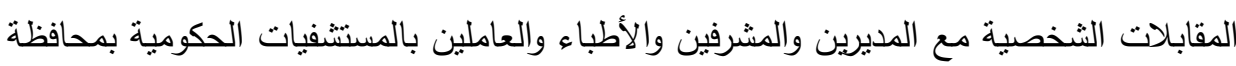

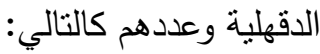

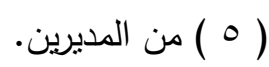

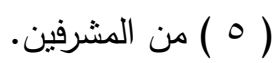

(1) (1) من الأطباء (تخصصات مختلفة). ( • (1) من العاملين (أقسام إدارية مختلفة).

هذا بالإضافة إلى الملاحظات الثخصية للباحثين أثناء المقابلات التى توصل لهشكلة الثلة

$$
\text { الدراسة من خلال الثواهد التى يتم رصدها . }
$$




\section{وهدف الباحثون من الدراسة الاستطلاعية إلى:}

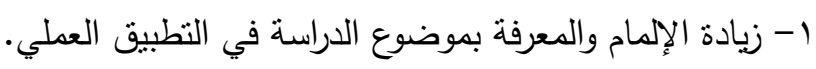

r- استكثاف مستوى ممارسة المراجعة الداخلية للوقوف على الأسباب السلبية التى تعوق من ليطن

وجودها وإمكانية تطبيقها.

r- معرفة أسباب انخفاض مستوى مشاركة المعرفة والعزوف عنها في بعض الحالات والتي

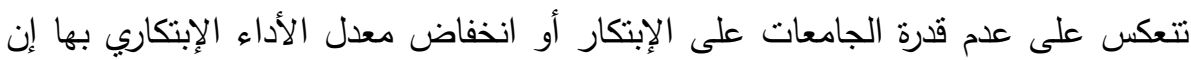

\section{وتوصل الباحثون نتيجة إجرائه للاراسة الاستطلاعية إلى الآتي:}

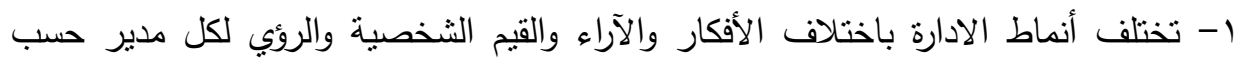
طريقة فهمه لطبيعة عمله ودوره الوظيفي ومسئولياته الروتينية ، مما يجعل اهتمام المديرين

$$
\text { يقل نوعا ما تجاه دعم وتحفيز الاهتمام بمنظومة جودة الخدمات الصحية. }
$$

r- يفتقر بعض الدديرين والمشرفين والأطباء إلى معرفة أهمية منظومة المراجعة الداخلية في دئه

تطوير الخدمة الصحية.

r- وجود ضعف ملحوظ في تثجيع كافة الفئات التي قام الباحثون باستجابتهم وملاحظتهم

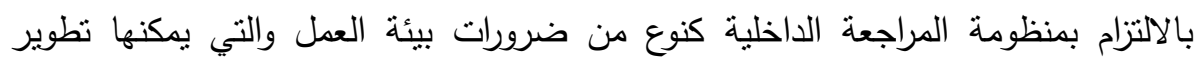

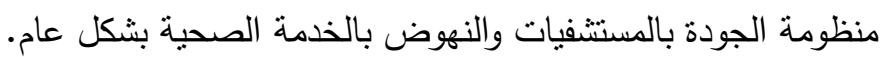

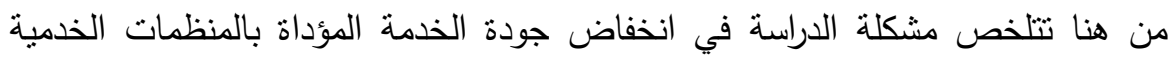
الحكومية وعدم الالتزام تلك المنظمات بالعديد من الاتشتراطات والتشريعات البيئية خاصة

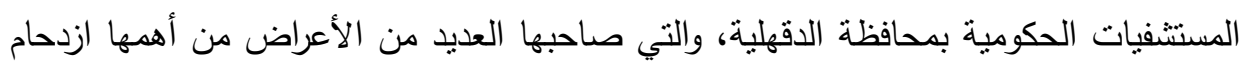

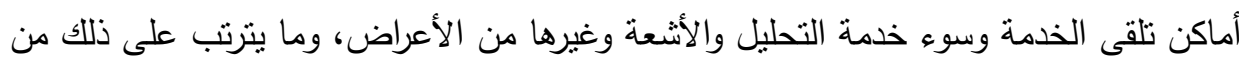

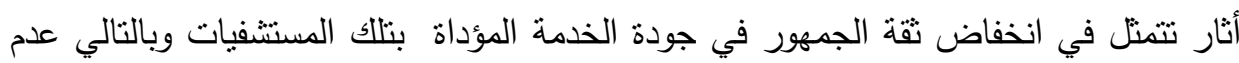

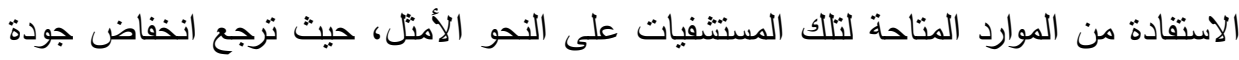

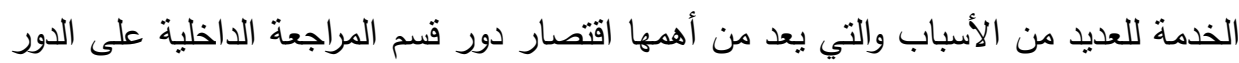


التقليدي المنمنل في مراجعة مستتدات الصرف وعدم قيامه بأي دور في توفير البيانات والتقارير المالية والتثغيلية اللازمة لإدارة المنظمة للارتقاء بجودة الخدمات المؤداة والأداء البيئي مما يحتم ضرورة نطوير أداء أقسام المراجعة الداخلية في ضوء معايير مستويات الأداء المهني ليتثى لها لهاء المساهمة الفعالة في دعم عملية اتخاذ القرار والاستفادة القصوى من جميع الموارد المتاحة لللنظمة ومن ثم تحسين جودة الخدمات المؤداة والأداء البيئي لتلك المنظمات.

\section{أهمه التصواسة.}

تتمثل أهمية الدراسة فى جانبين الاول نظرى و الثانى عملى (تطبيقي) أما الجانب النظرى

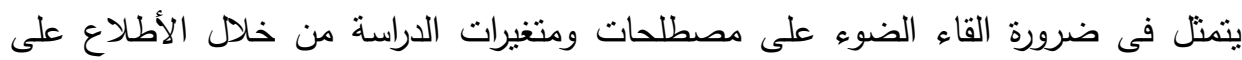
الدراسات السابقة ووضع أطار نظرى للمراجعة الداخلية وجودة الخدمات الصحية و الأداء البيئي

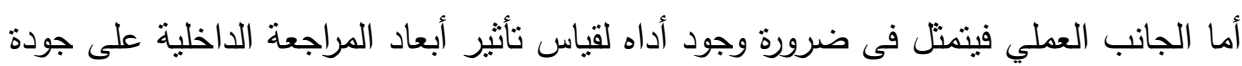

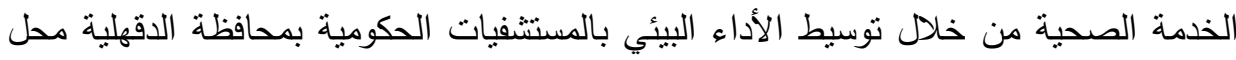
الدراسة، ووضع إطار مقترح لنظوير دور المراجعة الداخلية كمدخل لتحسين جودة الخدمة الصحية والأداء البيئي بالمسنتفيات الحكومية.

\section{أهسا هن القراسم.}

تهدف الدراسة الحالية إلي:

1- تقييم أداء المراجع الداخلي في المنظمات الخدمية في ضوء معايير مسنويات الأداء المهني ودوره في تحسين جودة الخدمة والأداء البيئي في ظل النمو المطرد في حجم المنظمات ومحدودية الوقت المتاح للمراجع الخارجي لفحص القوائم المالية والتتغيلية لهذه المنظمات.

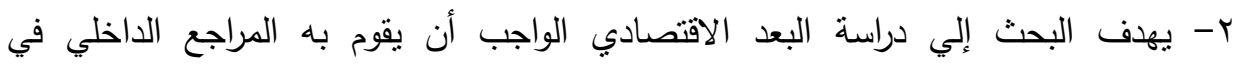

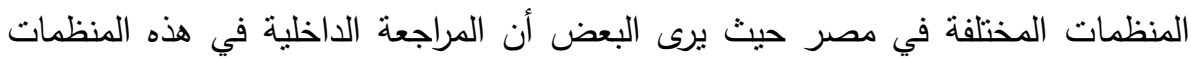

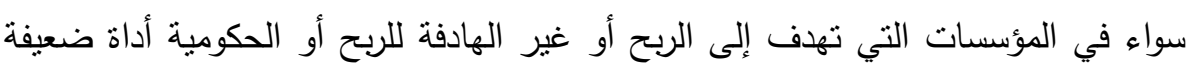
للغاية ولا تلعب أي دور اقتصادي في هذه المنظمات والمؤسسات. 
r- دراسة مدى تطبيق إدارة المراجعة الداخلية لمتطلبات ومبادئ ومفاهيم جودة الخدمة مع محاولة تحديد أهم هذه المنطلبات الواجب على إدارة المراجعة الداخلية بذل العناية الكافية تجاه الوفاء بها. ع - اختبار علاقة و تأثثر أبعاد المراجعة الداخلية على جودة الخدمة الصحية من خلال توسيط الأداء البيئي في المستشفيات الحكومية بمحافظة الدقهلية محل الدراسة. ه- وضع إطار مقترح لنطوير دور المراجع الداخلي في تحسين جودة الخدمة الصحية والأداء

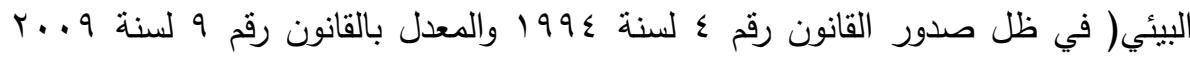
الخاص بالقواعد والإجراءات والضوابط الواجب إتباعها للحد من معدلات تلوث البيئة) وذلك بقطاع الخدمات الحكومية بشكل عام وبالمستشفيات الحكومية بشكل خاص.

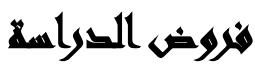

- لا نوجد علاقة ذات دلاله إحصائية بين المراجعة الداخلية بأبعادها ( تطبيق نظام محكم لأعمال المراجعة الداخلية - القيام بعملية المراجعة الداخلية وفق المعايير المهنية الواجبة-

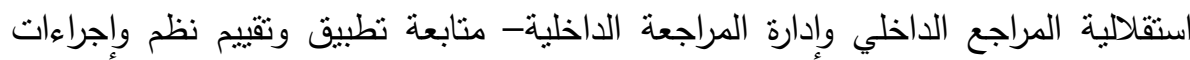
المراجعة الداخلية) والأداء البيئي بأبعاده ( دور المراجع الداخلي في مجال المراجعة البيئيةأهمية الأداء البيئي بالمستشفيات-اهتمام المستثفيات الحكومية بقيام المراجعين الداخليين في تقييم الأداء البيئي -مزايا المراجعة البيئية).

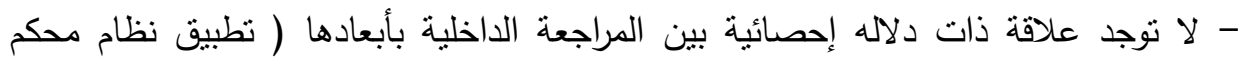

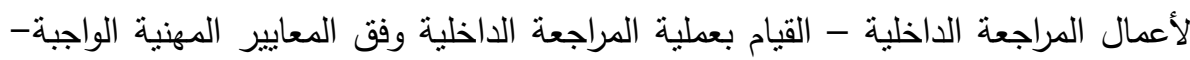

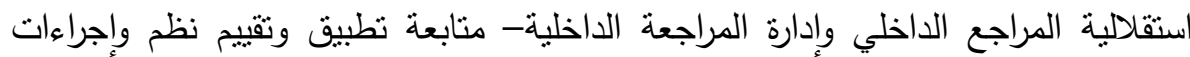
المراجعة الداخلية) وجودة الخدمة الصحية بإبعادها(الجوانب الملموسة - الاعتمادية الاستجابة-الضمان-التعاطف). 
- لا توجد علاقة ذات دلاله إحصائية بين الأداء البيئي بأبعاده ( دور المراجع الداخلي في

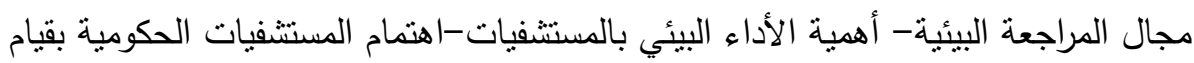

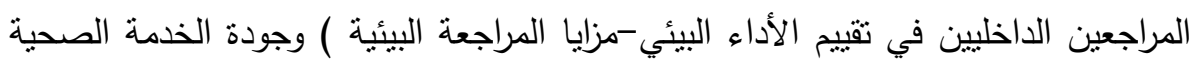
بإبعادها (الجوانب الملموسة- الاعتمادية- الاستجابة- الضمان -التعاطف ) ).

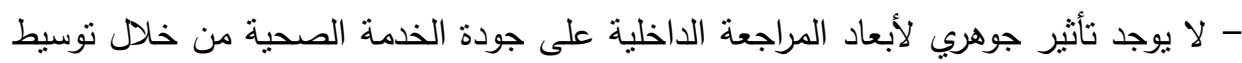
الأداء البيئي في المستشفيات الحكومية بمحافظة الدقهلية محل الدراسة.

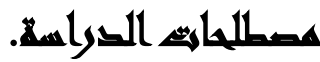

الاطار: يعرف الإطار بوجه عام بأنه تصوير أو تمنيل النظام المراد دراسته في شكل ابسط،آخذا في الاعتبار العوامل أو العناصر (المتغيرات) الأساسية ومهملا ما هو غير أساسي

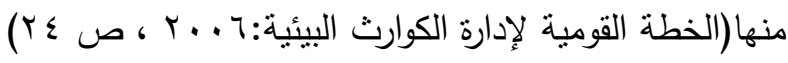

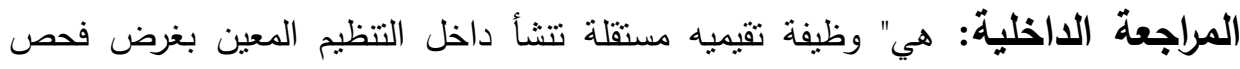
وتقييم الأنشطة التي يقوم بها هذا التتظيم وتهدف إلي مساعدة الأفراد داخل التتظيم للقيام بالمسئوليات المنوطين بها بدرجة عالية من الكفاءة وذلك عن طريق توفير التحليل، والتقييم، والتوصيات، والمشورة، والمعلومات التي تتعلق بالأنشطة التي تتم مراجعتها(فتحي السوافيرى، بهن

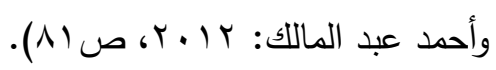

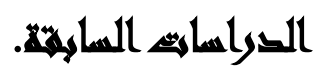

\section{دراسةة: (Ebrahim Jaafari \&Dila Agrizzi; Faizollah)}

هدفت الاراسة إلي تحديد واقتراح تدابير أداء برامج الاعتماد في الرعاية الصحية، واستخدام بعض التدابير كوسيلة لدعم قرار قد اتخذته السلطات وصناع القرار لتقييم برامجها خلال فتزة

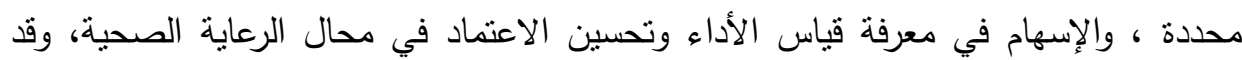

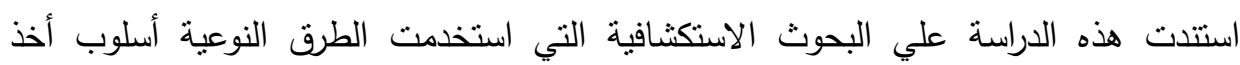

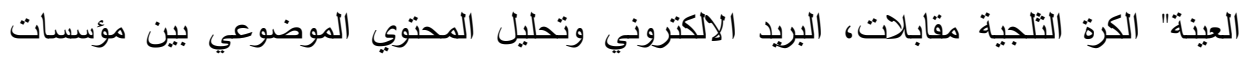


الرعاية الصحية والجامعات والمؤسسات المصاحبة للاعتماد في كندا، أستراليا وفرنسا، وكانت نتائج التحليل أدت الي مفاتيح لقياس وتقييم برامج الاعتماد والمقاييس التي من المدكن

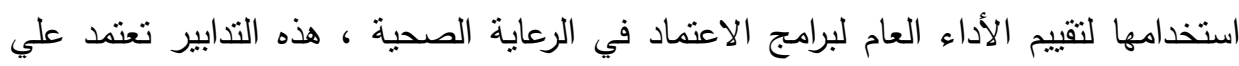

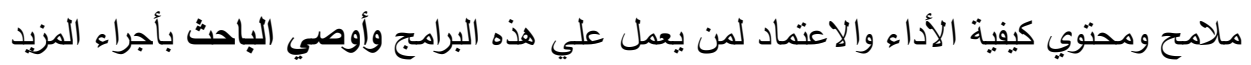
من البحوث التجريبية والمستمرة في محاولة تحقيق علامات مؤكدة وبناءة إضافية من تدابير

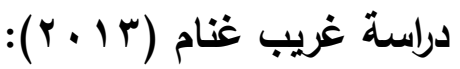

هدفت هذه الدراسة إلى: وضع إطار مقترح لتفعيل دور المراجعة الداخلية على أساس الخطر

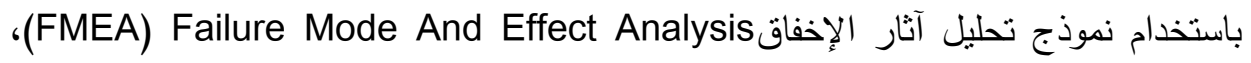
وتعرف على الدور المستحدث للمراجعة الداخلية في ضوء إدارة المخاطر، وتوصلت الدراسة إلى

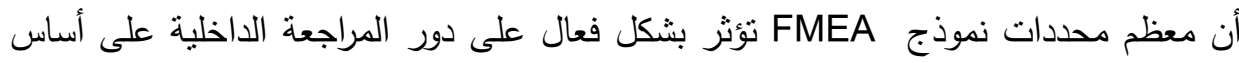

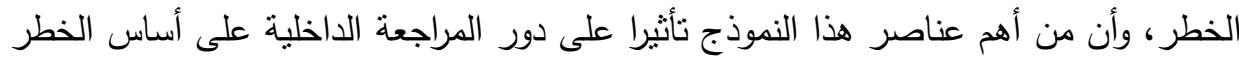
هي تسهيل أنشطة تحديد وفحص الأخطار ، وضع خطة استراتيجية لإدارة نموذج أثنار الإخفاق، وأوصت الدراسة بالتحديد الجيد للمخاطر والعطليات المرتبطة بها في كل عملية مراجعة، وتوفير الإنه الإدارة المطلوبة والدعم الفني من قبل الإدارة لجميع فرق النموذج.

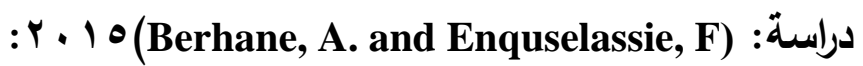

هدفت الاراسة إلي التعرف علي تفضبلات المرضى لخصائص خدمات الرعاية الصحية ، والتعرف علي تأثير هذه الخصائص في عملية اختيار المستشفى بمنطقة أمهارا ، شمال أثثيوبيا، وتم جمع بيانات الدراسة من خلال استقصاء . .010 مريض من المرضي الداخليين والمرضي فئي بالعيادة الخارجية للمستشفيات العامة محل الدراسة، ونم تحليل بيانات الدراسة عن طريق ليقي البرنامج الإحصائي S T A T A وتوصلت الاراسة إلي أن العناصر التالية تؤثز علي اختيار

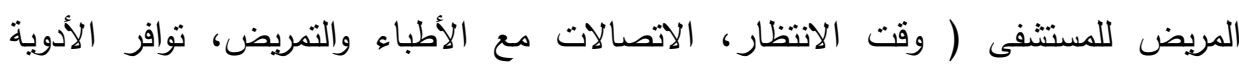

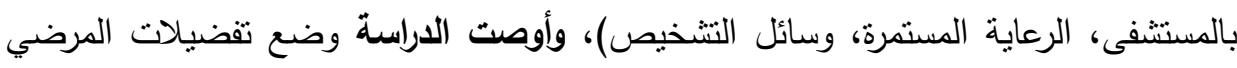


محل الاعتبار عند الاعداد للخدمات الصحية بحيث تثنتل علي كل ما من شأنه أن يرضي العملاء لضمان وصول الخدمة بشكل جيد. دراسة خالا مصباح (7 17 ب):

هدفت الدراسة إلي تفعيل وظيفة المراجعة الداخلية في ظل بيئة نظم تخطيط موارد المنظمة وأثرها في دعم المراجعة الداخلية علي أساس الخطر ، وذلك من خلال دراسة ميدانية بالاعتماد علي المنهج الوصفي التحليلي وقائمة استبيان طبقت علي المراجعين الداخليين وموظفي نظم المعلومات وموظفي إدارة المخاطر في القطاع المصرفي، وتوصلت الدراسة إلي وجود اتفاق معنوي بين فئات البحث حول ضرورة توفر مجموعة من المهارات العلمية والعملية لأفراد المراجعة الداخلية في بيئة نظم تخطيط موارد المنظمةERP، حيث يعمل ذلك على تعزيز المهارات التقنية والخبرة العملية في مجال تكنولوجيا المعلومات لديهم من أجل التعامل مع المهام الجديد المتمنلة في نظم تخطيط الموارد، ووجود اتفاق معنوي بين المبحوثين حول تفعيل وظيفة مئة المراجعة الداخلية في ظل بيئة نظم تخطيط الموارد بما يؤدي إلي موضوعية واستقلالية وظيفة

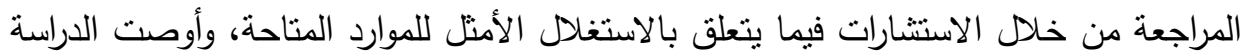
بتوفير الامكانات المطلوب توافرها بالمراجعين في ظل بيئة نظم تخطيط موارد المنظمة.

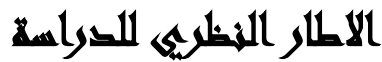

تعتبر المراجعة الداخلية إحدى الوظائف التي يقوم بها المراجع الداخلي، وتعتبر أداة لفحص نظم الإدارة وتقييم أداء المنشأة واختبار مدي نوافق عملياتها ومخرجاتها مع البيئة

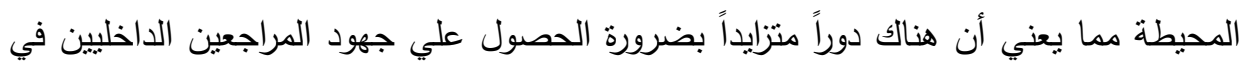

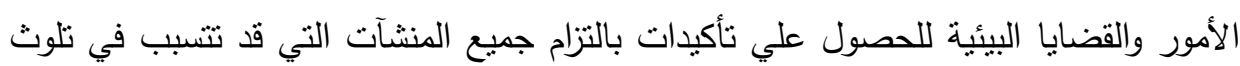
البيئة بتطبيق القوانين واللوائح البيئية والتي تم تنريعها لحماية البيئة والمجتمع (إيناس نبوي:

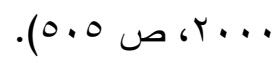


كما شهدت المراجعة نمواً وتطوراً كبيراً خلال العقدين الماضيين عندما أدركت الإدارة العليا والإدارة البيئية بالوحدات الاقتصادية أن المراجعة هي أحد المكونات الأساسية في نظم الإدارة فئرة

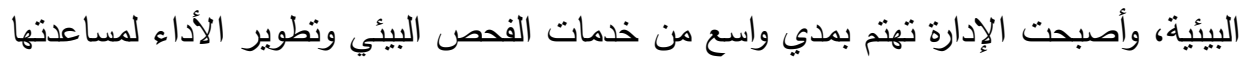

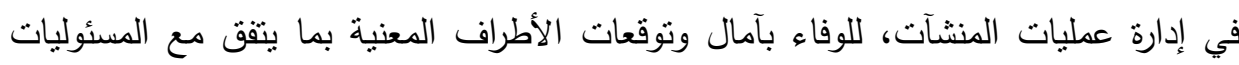
الجديدة وتقع هذه الاختبارات وعمليات الفحص المختلفة تحت عنوان المراجعة. ولما كانت المراجعة أحد الروافد الهامة في منظومة الاهنمام والمحافظة علي البيئة، فإن النان الاهتمام بها جاء مع بدء عام 1917 حين أصدرت جمعية حماية البيئة سياسة المراجعة البيئة

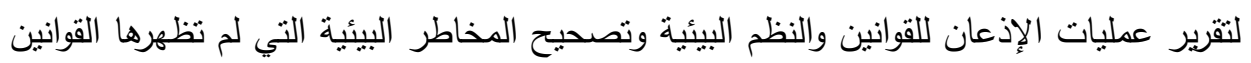

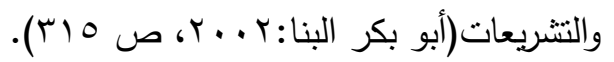
وتعرف المراجعة بأنها "فحص انتقادي دوري منظم وموثق وموضوعي بواسطة المنشأة أو بوري بواسطة جهة مستقلة ذات سلطة قانونية للعمليات الإنتاجية وما يرتبط بها من أنشطة فرعية

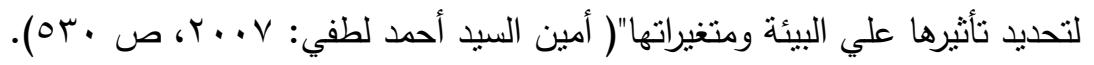
خصائص المراجعة الاخلية: - أنها وظيفة تتشأ داخل المنشأة. - يقوم بها موظفون من داخل المنشأة وتابعون لها. - مهنها فحص وتقييم أنشطة المنشأة. - لا يؤدي القيام بها إلي إنجاز أعمال تتفيذية. - أن يتم تأديتها بطريقة موضوعية.

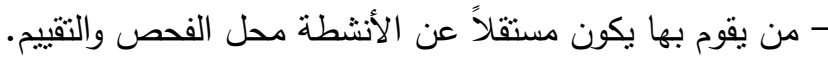

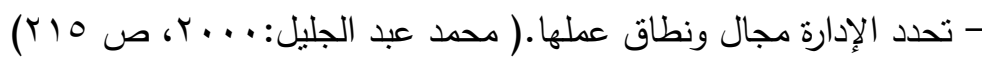
- قيام إدارة المراجعة بتقديم العون للإدارة عن طريق التقارير التي ترفعها إليها والتي تساعدها في اتخاذ قراراتها وتؤكد مدي انتظام ودقة كل من نظامي الضبط الداخلي والمحاسبي(محمد وند

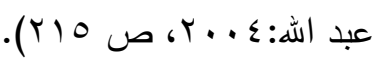


أهداف المراجعة الداخلية: تهدف المراجعة إلي مساعدة الإدارة في القيام بوظائفها علي أكمل وجه عن طريق تزويدها بالتحليل والتقييم المناسب عن الأنشطة التي ينت مراجعتها. - فحص وتقييم مدي سلامة وكفاية نظم الرقابة المحاسبية والمالية وغيرها من نظم الرقابة المطبقة بالمشروع والعمل علي الارتقاء بكفاءة هذه النظم بالتكاليف المناسبة. - التأكد من الالنزام بالخطط والسياسات والإجراءات الإدارية الموضوعة. - التأكد من حماية أصول المنشأة من السرقة والاختلاس والغش والتلاعب. - التأكد من مصداقية المعلومات التي ينتجها نظام المعلومات الإداري بالمنشأة. - تقييم كفاءة الأداء فيما يتعلق بالمهام التي كلف العاملون بالقيام بها. - فحص وتقييم نظم إدارة المخاطر والرقابة والتحكم. - تقديم التوصيات اللازمة لتحسين الخطط والنظم والسياسات والإجراءات الخاصة بكل هذه (Office of Thrift Supervision; (2009),p.10).الجوانب أنشطة المراجعة الداخلية: يختلف مجال وأهداف المراجعة الداخلية من شركة لأخرى حيث يعتمد ذلك علي حجم وهيكل المنظمة ومتطلبات إدارتها، وفي جميع الأحوال تتضمن أنشطة المراجعة الداخلية ما يلي:- - الئي - فحص الأنظمة المحاسبية وأنظمة الرقابة الداخلية، واقتراح التحسينات بشأنها. - فحص المعلومات المالية والعمليات وهذا يشمل فحص الوسائل المستخدمة لتحديد وقياس والثقرير عن جميع المعلومات مع إجراء اختبارات مفصلة للعمليات(محمد عبد اله :ـ ...T،

- التركيز علي مخاطر النشاط الرئيسية والتعامل مع الشككلات المتعلقة بالمخاطر . - تحديد المخاطر وإدارتها استراتيجياً ومن ثم فإن الخبرة في معرفة نظام الرقابة الداخلية وأساليب إدارة المخاطر تعتبر مصدر قوة للمراجعين الداخليين تمكنهم من القيام بتحديد 
- تحليل المخاطر حيث إن المراجع الداخلي لديه اهتمامين عند القيام بتحليل المخاطر . (Institute of Internal Auditors UK and Ireland;(2011), p.21).

\section{الاجباءايت المنهجية الستواسما}

مجتمع وعينة الدراسة: يتمثل مجتمع الدراسة من( المديرين والمراجعين الداخليين والقيادات الإدارية داخل المستشفيات الحكومية في محافظة الدقهلية، ومقدمي الخدمة ( العاملين والإداريين)، ويشمل مجتمع العاملين والبالغ 110 مفردة: جميع العاملين بالقطاع الصحي

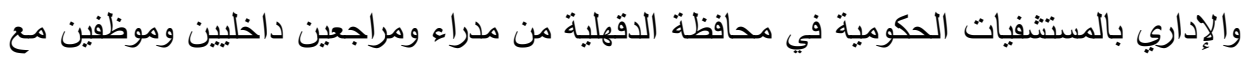
استبعاد من ليس لهم علاقة بالأنشطة التي تنتاولها الدراسة كالخدمات الإدارية والمعاونة والأمن

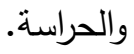

ولتحديد حجم العينة بطريقة معادلة ستيفن ثامبسون وبإفتراض أن الظاهرة محل الدراسة

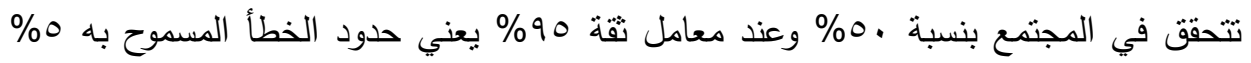
فقد تم إستخدام المعادلة التالية لحساب حجم العينة بتطبيق معادلة ستيفن ثامبسون، سبد محمد

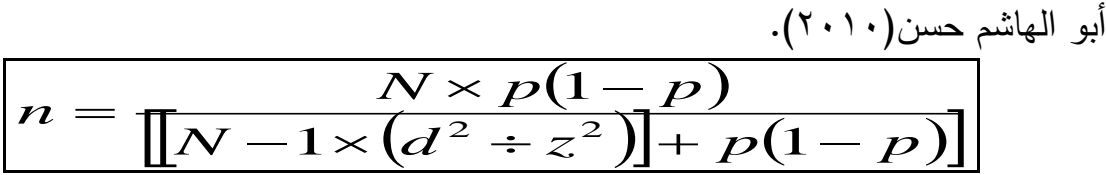
N

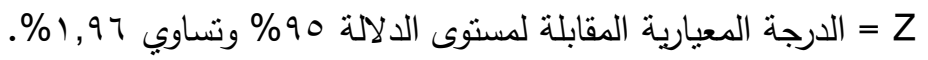
\% d نسبة الخطأ وتساوي

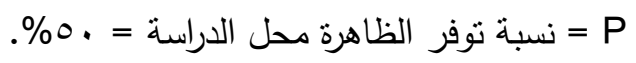

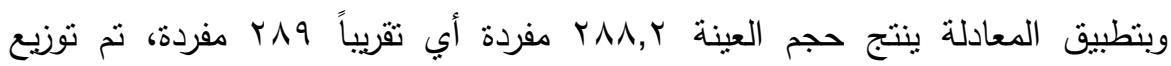
الاستمارات عثوائيا على فئات الدراسة مع الأخذ في الاعتبار التوزيع النسبي لفئات الدراسة

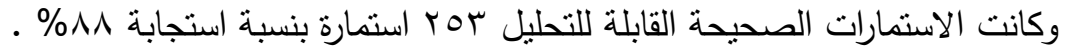


وقد حرص الباحثون على توزيع .م مفردة تفادياً لضياع بعض القوائم أو عدم استنفائها بشكل صحيح، أما عدد الاستمارات الموزعة على عينة الدراسة من المشاركين من المستتفيات الحكومية في محافظة الدقهلية والمردود منها، وقد قام الباحثون باستخدام طريقة النسبة والتتاسب حتى يتمكن من تمثيل مجتمع الدراسة من خلال تلك العينة، ويوضح الجدول رقم (1) ذللك: جدول رقم(1): توزيع حجم العينة الموزعة والمردودة للمشاركين من المستشفيات الحكومية

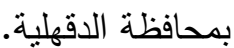

\begin{tabular}{|c|c|c|c|c|}
\hline نسبة الاستمارات & الاستمارات & الاستمارات & الاستمارات & 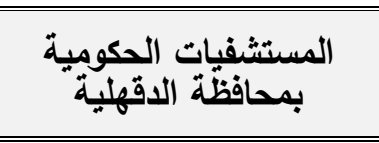 \\
\hline$\% \wedge 9$ & $1 \mathrm{~V}$ & 19 & 19 & مستشفى المنصورة الجامعي \\
\hline$\% 90$ & 11 & 19 & 19 & مركز الكلى والمسالك البولية \\
\hline$\% 90$ & 11 & 19 & 19 & مركز جراحة الجهاز الهضمى \\
\hline$\% \wedge 9$ & $1 \mathrm{~V}$ & 19 & 19 & مستشفي الطوارئ \\
\hline$\% \wedge 9$ & 17 & 11 & 19 & مركز طب وجراحة العيون \\
\hline$\% . \wedge 9$ & $1 \mathrm{~V}$ & 19 & 19 & مسنشفي الاطفال الجامعى \\
\hline$\% \wedge 9$ & 17 & 11 & 19 & مسنتفى الباطنة التخصصي \\
\hline$\% \wedge 9$ & $1 V$ & 19 & 19 & مركز الاورام \\
\hline$\% \wedge \mu$ & 10 & 11 & 19 & طلخا المركزي \\
\hline$\% \wedge \varepsilon$ & 17 & 19 & 19 & المنصورة العام الجديد \\
\hline$\% \wedge \wedge$ & $1 \varepsilon$ & 17 & 19 & المنزلة المركزي \\
\hline$\% \wedge 9$ & 17 & 11 & 19 & المنصورة العام القديم \\
\hline$\% \wedge \mu$ & 10 & 11 & 19 & السنبلاوين العام \\
\hline$\% \vee 7$ & 14 & IV & 19 & دكرنس العام \\
\hline$\% \wedge 9$ & 17 & 11 & 19 & آجا المركزي \\
\hline$\% \wedge$. & IT & 10 & 19 & منية النصر المركزي \\
\hline$\% \wedge \wedge$ & ror & r^9 & $\Gamma \cdot s$ & الاجمالي \\
\hline
\end{tabular}

المصدر: من إعداد الباحثّن.

أداة تجميع بيانات الدراسة الميدانية: قام الباحثون بتصميم قائمنين استقصاء لتجميع البيانات من مفردات الدراسة، حيث نم إعدادهما وتصميمها وتحليلهما بالخطوات الاربع الآتية: الخطوة الأولى: إعداد قائمة الاستقصاء فى صورتها الأولية: قام الباحثون بتصميم قائمنين

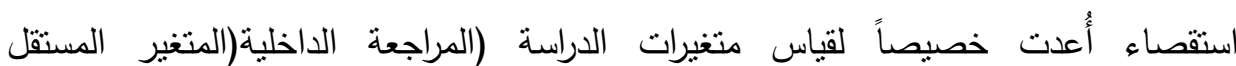


الرئيسي)وأبعادها -والمتغير التابع: (جودة الخدمة الصحية(المتغير التابع الرئيسي))) وأبعادها، -والمتغير الوسيط: الأداء البيئي وأبعاده، استمارة موجهة للمراجعين الداخليين والعاملين

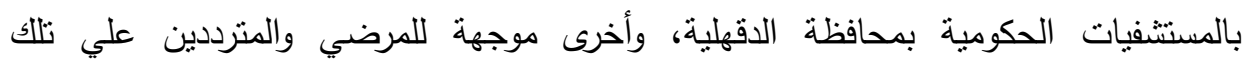

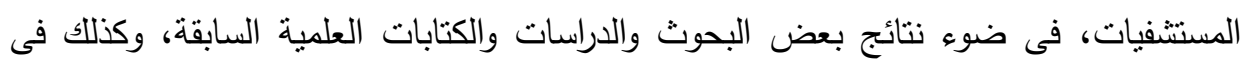

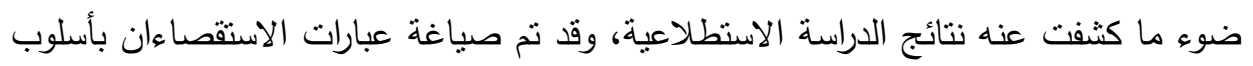
خبري وبألفاظ سهلة وبسيطة حتى تتفق مع المستوى الثقافي لبعض المستقصين بالمستشفيات

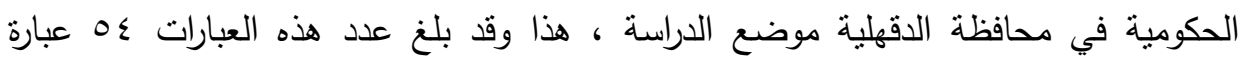
للاستمارة الموجهة للمراجعين الداخليين والعاملين بالمستشفيات الحكومية بمحافظة الدقهلية، وبلغت إع عبارة للاستمارة الموجهة للمرضي والمترددين علي تللك المستشفيات. الخطوة الثانية: اختبار صدق وثبات الاستقصاء: وقد قام الباحثون باختبار قائمة الاستقصاء

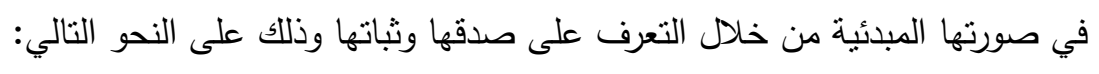
اختبار صدق الاستقصاء: اعتمد الباحثتن على نوعين من الصدق، وهما صدق المحكمين

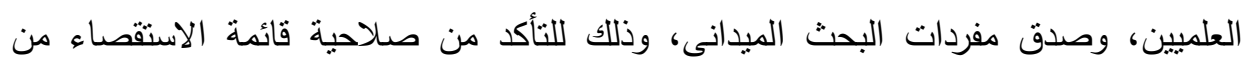

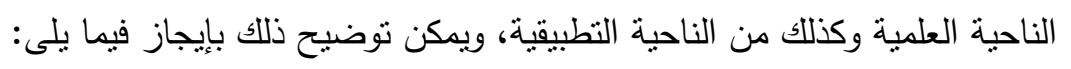

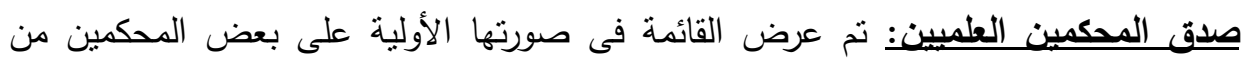

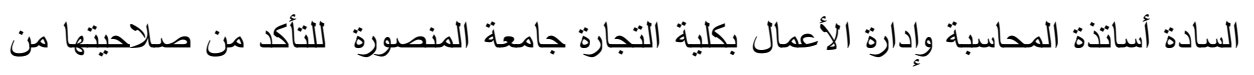
الناحية العلمية، وقد أبدى هؤلاء المحكمين بعض الملاحظات على قائمني الاستقصاء وذلك من النواحى الثكلية واللغوية والموضوعية حيث حذف بعضهم بعض الألفاظ واستبدالها بألفاظ أخرى الخى

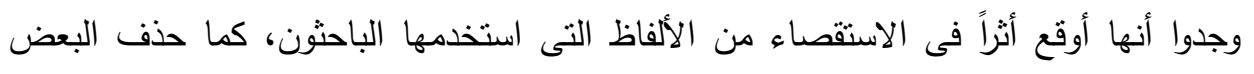
الآخر بعض العبارات، ورأى إضافة عبارات أخرى لتكون ذات دلالة واضحة، وقد الخذ الخد الباحثون

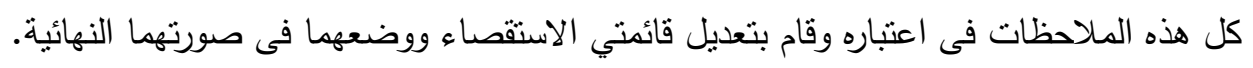

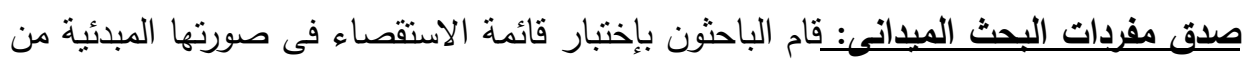
خلال التعرف على صدقها وثباتها وذلك على النحو التالى: 
•• قام الباحثون بإجراء اختبار مبدئى لقائمة الاستقصاء حيث تم عرضها فى صورتهما الأولية على ثلاثون طبيباً وعاملاً بالمستشفيات الحكومية بمحافظة الدقهلية، وذلك للتأكد من بساطة الصياغة ووضوح اللغة، وللتأكد أيضاً من صلاحيتها من الناحية الميدانية.

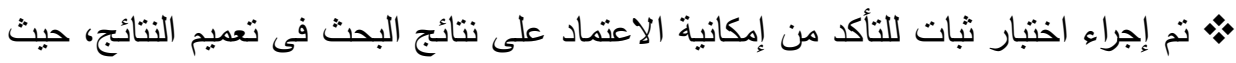

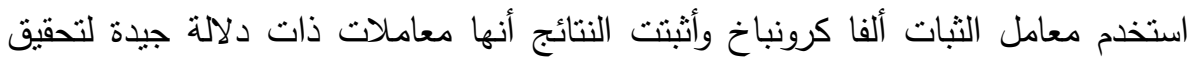
أهداف البحث، ويمكن الاعتماد عليها فى تعميم النتائج على مجتمع الدراسة. جدول رقم(r): معاملى الثبات لألفا كرونباخ والصدق الذانى لاستمارتي الاستقصاء

\begin{tabular}{|c|c|c|c|}
\hline الصدامل & $\begin{array}{c}\text { معامل } \\
\text { (Alpha) } \\
\text { (Alpha }\end{array}$ & البيـان & 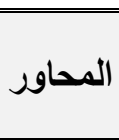 \\
\hline 0.970 & 0.940 & المراجعةٌ الداخلية & الأول \\
\hline 0.818 & 0.669 & تطبيق نظام محكم لأعمال المراجعة الداخلية & آولا \\
\hline 0.834 & 0.695 & القيام بعملية المراجعة الداخلية وفق المعايير المهنية الواجبة & ثنانيا \\
\hline 0.971 & 0.943 & استقلالية إدارات المراجعة الداخلية & ثالثا \\
\hline 0.939 & 0.881 & متابعة تطبيق وتقييم نظم واجراءات المراجعة الداخلية. & رابعا \\
\hline 0.975 & 0.950 & الأداء البيئي & 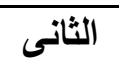 \\
\hline 0.861 & 0.741 & دور المراجع الداخلي في مجال المراجعة البيئية & أولا \\
\hline 0.933 & 0.870 & أهمية الأداء البيئي بالمستشفيات & ثانيا \\
\hline 0.981 & 0.962 & اهتمام المستشفيات الحكومبية بقيام المراجعين الداخليين في البياء & 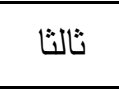 \\
\hline 0.864 & 0.746 & مزايا المراجعة البيئية & رابعاً \\
\hline 0.786 & 0.618 & جودة الخدمة الصحية & 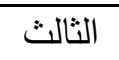 \\
\hline
\end{tabular}

المصدر: من إعداد الباحث من واقع مخرجات برنامج SPSS

الخطوة الثالثة: استيفاء بيانات قوائم الاستقصاء وإعدادها للتحليل الإحصائى: قام الباحثون فى بـ

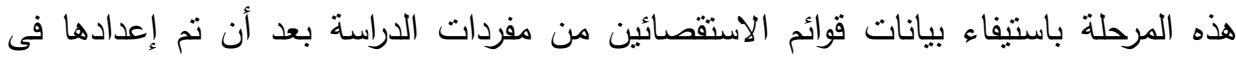
صورتها النهائية، حيث قام الباحثون بالتوجه إلى بعض المستشفيات الحكومية بمحافظة الدقهلية قيد الدراسة لعرض قوائم الاستقصائين على بعض العاملين والمرضي والمترددين بالمستشفيات

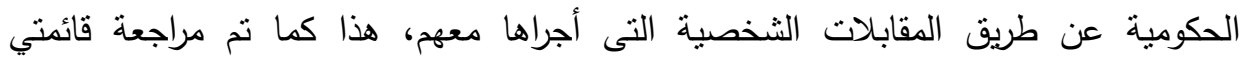


الاستقصاء بعد أن تمت الإجابة عليهما، ثم قام الباحثون بإدخال هذه البيانات للحاسب الآلى

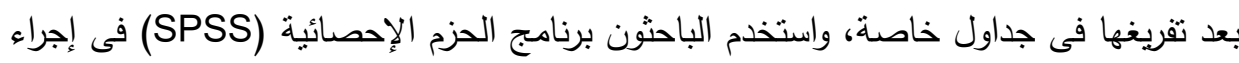

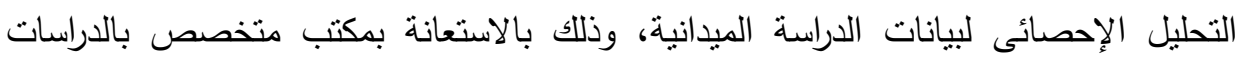
والتحليل الإحصائي.

الخطوة الرابعة: أساليب التحليل الإحصائي: اعتمد الباحثون على الأساليب التالية:

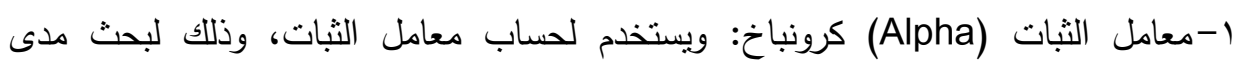
إمكانية الاعتماد على نتائج الدراسة الميدانية فى تعميم النتائج. r-الوصف الاحصائي لعينة الدراسة. r-الاحصاء الوصفى لمحاور الاستقصاء. ع-الصدق ( الإتساق) الداخلى: حيث يتم حساب معاملات الارتباط لبيرسون بين متغيرات الدراسة. ه-تقديرات نموذج الإنحدار الجزئى( معاملات المسار) لانحدار المتغير الوسيط ( متوسط آراء عينة الراسة حول الأداء البيئي) على المتغيرات المستقلة (أبعاد المراجعة الداخلية).

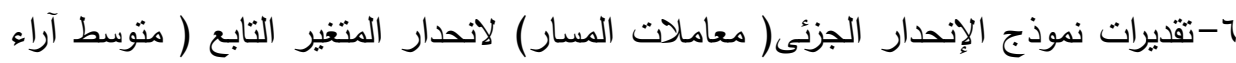
عينة الراسة حول جودة الخدمة الصحية) على المتغيرات المستقلة (أبعاد المراجعة الداخلية

$$
\text { والأداء البيئي). }
$$

واستخدم الباحثون برنامج الحزم الإحصائية (SPSS) فى إجراء التحليل الإحصائي لبيانات الدراسة الميدانية.

\section{مشوض الكوراسم}

الحدود الزمنية: تتمتل الحدود الزمنية للدراسة فى الفترة من يناير عام 17 ـب الي نهاية

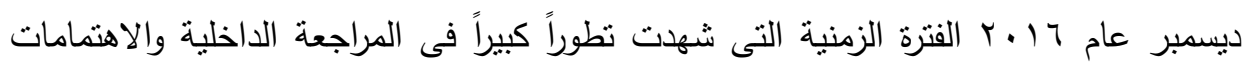
البيئية، والخدمات الصحية والإدارية التى تقدمها المستشفيات الحكومية في محافظة الدقهلية. 
الحدود المكانية: كما تتمنل الحدود المكانية للدراسة فى المستشفيات الحكومية في محافظة

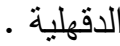

ويرجع اختيار الباحثون لهذه المستثفيات الى أنها تعد من أهم المستشفيات العاملة فى القطاع الصحي فى مصر من حيث نوافر الإمكانات والكوادر الفنية والبشرية اللازمة والنى يمكن من خلالها تصدير الخدمة الصحية للخارج ووضع نموذج يحتذى به فى كافة المستشفيات الأخرى فى مصر وكذلك للصلة الوثيقة التي تربط الباحثون بهذه المستشفيات. الحدود البشرية: وقد شملت الدراسة الحدود البشرية (الدديرين والمراجعين الداخليين والقيادات الإدارية والعاملين والإداريين بهذه المستشفيات ويشمل مجتمع العاملين : جميع العاملين بالقطاع الصحي والإداري بالمستشفيات الحكومية في محافظة الدقهلية من مدراء ومراجعين داخليين وموظفين مع استبعاد من ليس لهم علاقة بالأنشطة التي تتتاولها الدراسة كالخدمات الإدارية والمعاونة والأمن والحراسة، وكذلك من المرضى والمترددين على تلإلك المستشفيات.

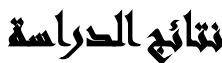

يعرض الباحثون فيما يلى نتائج الدراسة وذلك من خلال التحليل الاحصائي لمنغيرات

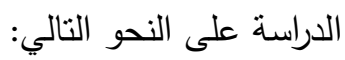
جدول رقم(؟): الاحصاء الوصفى لأبعاد وعناصر المراجعة الداخلية.

\begin{tabular}{|c|c|c|}
\hline انحراف & وسط & 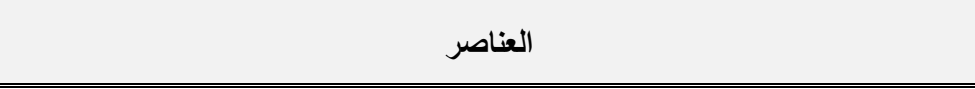 \\
\hline 0.36 & 3.61 & نطبيق نظام محكم لأعمال المراجعة الداخلية. \\
\hline 0.48 & 4.79 & تقوم المستشفى بتطبيق نظام محكم لأعمال المراجعة الداخلية مما بساعد في تحسين الأداء \\
\hline 0.68 & 4.35 & تطبيق نظام محكم لأعمال المراجعة الداخلية نقطة انطلاق ايجابية للمراجع الداخلي للقيام \\
\hline 0.57 & 4.40 & يقوم المراجع الداخلى بالالتزام التام بسياسات ومعايير جودة المراجعة الداخلية بالمستشفى. \\
\hline 0.75 & 4.34 & 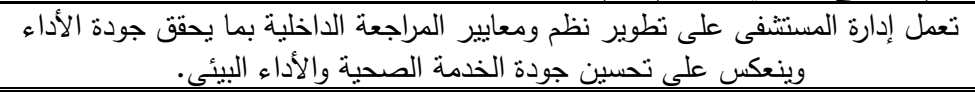 \\
\hline
\end{tabular}


مجلة العلوم البيئية

معهد الدراسات والبحوث البيئية - جامعة عين شمس لينه

تابع جدول رقم(ץ):

\begin{tabular}{|c|c|c|}
\hline معيارى & حسابط & العناصر \\
\hline 0.50 & 1.79 & تضع إدارة المستشفى القوانين والتعليمات والاجراءات الماتلائمة لتصحيح أية اختلالات في \\
\hline 0.41 & 1.97 & تقوم إدارة المستشفى بوضع نظام جيد للحوافز والمكافآت لتشجيع الالتزام بمعايير المراجعة الداخلية. \\
\hline 0.77 & 4.31 & القبام بعملية المراجعة الداخلية وفق المعايير المهنبة الواجبة. \\
\hline 0.59 & 4.60 & تهتم المستشفى بالالتزام بالمعايير المهنية للمراجعة الداخلية على النحو المطلوب. \\
\hline 2.62 & 4.77 & يطلع قسم المراجعة الداخلية علي المعايير الدولية المستجدة ويعمل على تطبيقها في \\
\hline 1.28 & 3.74 & يتميز المراجع الداخلي بالقيام بعملية المراجعة وفق المعايير المهنية المطلوبة. \\
\hline 1.09 & 4.17 & تساعد إدارة المستشفى قسم المراجعة الداخلية عن طريق تحليل مؤشرات الجودة والأداء \\
\hline 0.94 & 4.13 & يتم التدريب المستمر لأفراد قسم المراجعة الداخلية على المعايير المهنية المطلوبة \\
\hline 0.58 & 4.39 & تتحقق إدارة المستشفى من تتفيذ أفراد المراجعة الداخلية للمعايير المهنية الواجبة وعرض توضئهات \\
\hline 0.75 & 4.34 & تعمل إدارة المستشفى على دراسة خطط التطوير والتغيير في نطم ومعايير المراجعة الداخلية. \\
\hline 0.91 & 4.00 & استقلالية المراجع الداخلي وادارات المراجعة الداخلية. \\
\hline 0.59 & 4.46 & 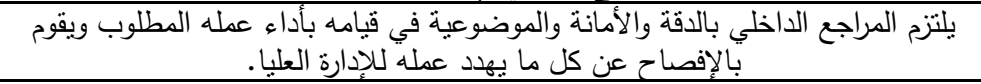 \\
\hline 1.12 & 4.01 & يقوم المراجع الداخلى باتخاذ قراراته بدون تحيز وبدون ضغوط إدارية. \\
\hline 0.94 & 3.76 & يقدم المراجع الداخلى تقاريره للإدارة العليا مباشرة مما بدعم استقلاليته. \\
\hline 1.00 & 3.85 & موقع إدارة المراجعة الداخلية في الهيكل النتظيمي يؤثر علي تحسين جودة الخدمة والأداء \\
\hline 1.28 & 3.74 & 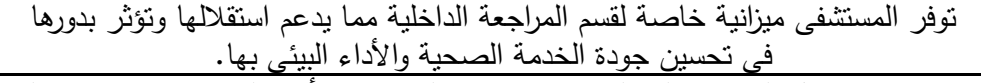 \\
\hline 1.09 & 4.17 & اختيار فريق عمل المراجعة الداخلية بكفاءة يؤثر علي المقدمةتوى أداء القسم ومن ثم يؤثر علي \\
\hline 0.70 & 3.60 & متابعة تطبيق وتقييم نظم واجراءات المراجعة الداخلية. \\
\hline 0.94 & 4.13 & تقوم إدارة المستشفى بمتابعة إدارة المراجعة الداخلية من حيث المبالة تطبيق نظم واجراءات \\
\hline 0.95 & 4.11 & يتم التقييم المستمر لأعمال إدارة المراجعة الداخلية من قبل إدارة المستشفى لدعم كفاءة أداءها \\
\hline 0.78 & 3.86 & 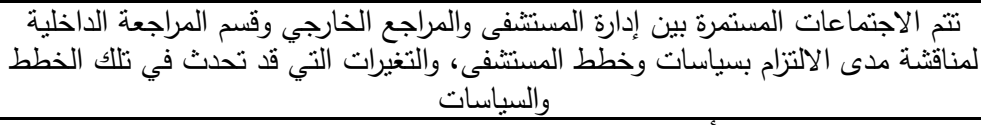 \\
\hline 0.85 & 3.94 & تتاقش إدارة المسنتشفى أفراد المراجعة الداخلية بما بواجهرح من عقبات والعمل على حلها \\
\hline 1.04 & 3.90 & تتابع الإدارة مدى استجابة قسم المراجعة الداخلية لتقارير إدارة المسنشفى والمراجع الخارجي \\
\hline 0.74 & 1.68 & تتلقى إدارة المراجعة الداخلية تقارير من إدارة المستشفى ومن المراجع الخارجي لتقييم أداء أفرادها \\
\hline
\end{tabular}


ويتضح من الجدول ارتفاع منوسط الآراء حول العنصر (تقوم المستشفى بنطبيق نظام محكم لأعمال المراجعة الداخلية مما يساعد في تحسين الأداء البيئي وجودة الخدمة الصحية)

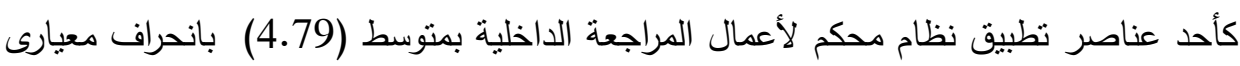
(0.48) أي أن معظم الآراء تتراوح مابين موافق وموافق تماماً وتميل الى أن تكون موافق تماماً،

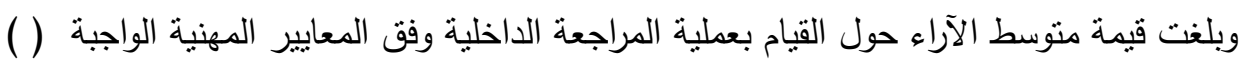
4.31 بانحراف معيارى (0.77)، أي أن معظم الآراء تتراوح مابين موافق وموافق تماماً وتميل الى أن تكون موافق، ويتضح من الجدول انخفاض قيمة منوسط الآراء حول العنصر (تنلقى إدارة المراجعة الداخلية تقارير من إدارة المستتفى ومن المراجع الخارجي لتقييم أداء أفرادها ) كاحدعناصر منابعة نطبيق وتقييم نظم وإجراءات المراجعة الداخلية. بمنوسط (1.68 ) بانحراف معيارى (0.74)، أي أن معظم الآراء نتراوح مابين غير موافق وغير موافق على الاطلاق

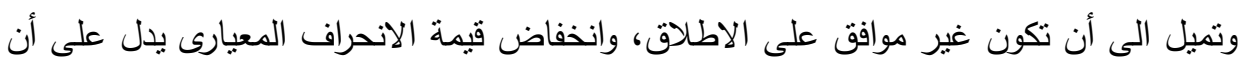
خفاض التباين فى الآراء او اتفاق عينة الدراسة فيما بينها حول أبعاد المراجعة الداخلية.

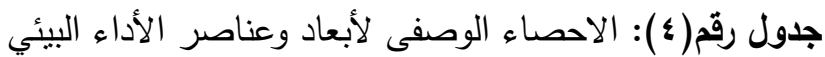

\begin{tabular}{|c|c|c|}
\hline 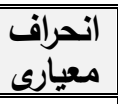 & سبط & العناصر \\
\hline 0.49 & 4.34 & دور المراجع الداخلي في مجال المراجعة البيئية \\
\hline 1.04 & 4.12 & المراجع الداخلى الى متابعة السياسات البيئية في المسنتشفي \\
\hline 0.57 & 4.31 & يمارس المراجع الداخلى مهام المراجعة البيئية بكفاءة. \\
\hline 0.60 & 4.38 & تسعى المستشفى الى تدريب وتأهيل المراجعين الداخليين للمراجعة البيئية. \\
\hline 0.61 & 4.56 & المراجع الداخلى الى التركيز على تطوير الأداء البيائى بالمستشفى. \\
\hline 0.54 & 4.34 & يقوم المراجع الداخلى بتقييم الآداء البيئي بالمستشفى. \\
\hline 0.72 & 3.99 & أهمية الآداء البيأي بالمستشفيات \\
\hline 0.73 & 4.36 & تأخذ المستشفى بعين الاعتبار الأثر البيئي عند القيام بنشاطاتها بحيث تكون اقل \\
\hline 0.55 & 4.42 & تهتم المستشفى باختيار الآلات التي تناعد على التقليل من التلوث الناتج عن \\
\hline 1.16 & 3.79 & تحرص المستشفى على النظافة المستمرة لدورات المياه وأماكن الانتظار . \\
\hline 0.88 & 3.64 & تهنت المستشفى بالتخلص من المخلفات بطرق حديثة وآَمنة. \\
\hline 0.96 & 3.73 & تستخدم المستشفى نظام مراجعة داخلية بيئية فعال. \\
\hline 0.96 & 3.82 & ستشفيات الحكومية بقيام المراجعين الداخليين فى تقييم الأ \\
\hline
\end{tabular}


تابع جدول رقم(ع ): الاحصاء الوصفى لأبعاد وعناصر الأداء البيئي

\begin{tabular}{|c|c|c|}
\hline انحراف & حسابط & العناصر \\
\hline 1.22 & 3.54 & يقوم قسم المراجعة الداخلية في المستشفي بممارسة الرقابة على فعاليات الأنشطة \\
\hline 1.06 & 4.03 & توجد داخل المستشفى سياسات بيئية محددة ينتم الالتزام بها، وبرامج بيئية \\
\hline 1.00 & 3.92 & تقوم المسنتفى بالوفاء بمسؤولياتها تجاه البيئة المحيطة. \\
\hline 1.00 & 3.92 & تسعى المستشفى للقيام بأعمالها ألبيثيثة النتافذة. مع متطلبات القوانين \\
\hline 0.82 & 3.68 & تقوم المستشفى بالمراجعة الداخلية لَّ نشطة البيئية بشكل طوعى. \\
\hline 0.54 & 4.13 & مزايا المراجعة البيئية \\
\hline 0.90 & 3.77 & قيام المستشفى بالمراجعة الداخلية البيئية يؤدي إلى تحسين الآداء البيئي \\
\hline 0.99 & 3.69 & قيام المستشفى بالمراجعة الداخلية البيئية يؤدي إلى تحسين علاقة المستشفى \\
\hline 0.61 & 4.59 & قيام المستثفى بالمراجعة الذاخلية البيئية يؤدي إلى تحسين جودة الخدمة الصحية \\
\hline 0.61 & 4.42 & تحرص المستشفى الحكومية علي تقديم خدماتها الصحية والإداريه بشكل بئية عالية \\
\hline 0.61 & 4.16 & 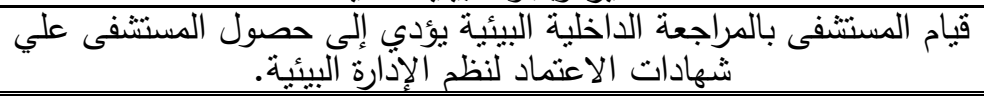 \\
\hline
\end{tabular}

ويتضح من الجدول ارتفاع منوسط الآراء حول العنصر (قيام المستشفى بالمراجعة الداخلية

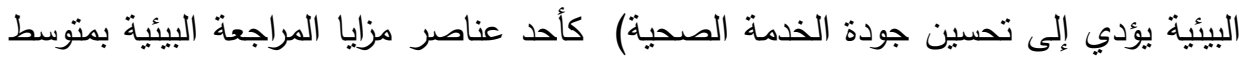
(4.59) بانحراف معيارى (0.61) أب أن معظم الآراء تتزاوح مابين موافق وموافق تماماً وتميل

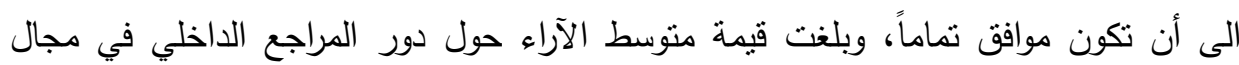

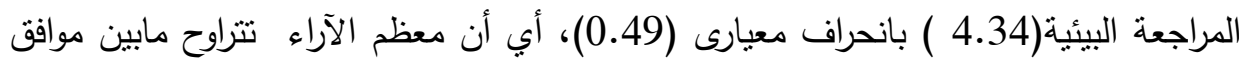

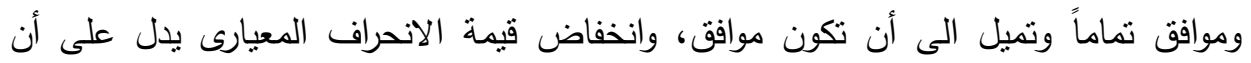

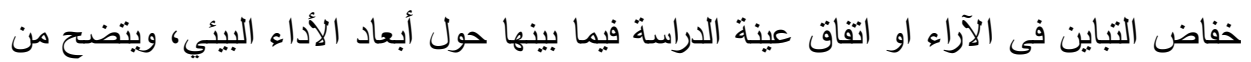

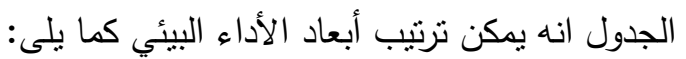


- دور المراجع الداخلي في مجال المراجعة البيئية

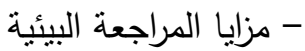
- أهمية الأداء البيئي بالمستشفيات البهاته - اهنمام المستشفيات الحكومية بقيام المراجعين الداخليين في تقييم الأداء البيئي. جدول رقم(•): الاحصاء الوصفى لأبعاد وعناصر جودة الخدمة الصحية

\begin{tabular}{|c|c|c|}
\hline معيارى & حسابط & العناصر \\
\hline 0.61 & 4.28 & يحرص المستشفى علي تحقيق جودة الخدمة الصحية الخاصة به \\
\hline 0.65 & 4.55 & 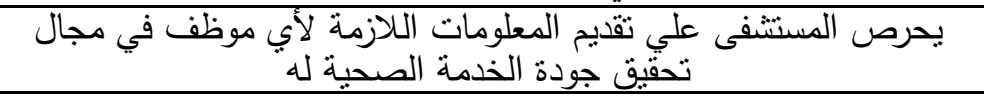 \\
\hline 0.55 & 4.58 & يمنلك المستشفى الروئية المستقلية لتحقيق جودة عالية للخدمة الصحية. \\
\hline 0.53 & 4.34 & يوفر المستتفى المناخ المناسب للمرضي والمترددين لتقديم الخدمة الصحية \\
\hline 0.57 & 4.49 & يتمتع العاملون بالمستشفى بالمهارة المهنية والمعرفة الفنية المطلوبة لإنجاز \\
\hline 0.71 & 2.79 & 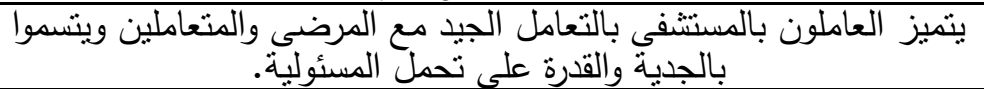 \\
\hline 0.69 & 4.49 & يؤدى العاملون المهام الوظيفية الموكلة إليهم طبقاً لمعايير الجودة المطلوبة. \\
\hline 0.51 & 4.58 & 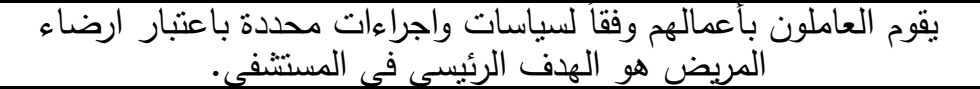 \\
\hline 0.78 & 4.03 & يبذل العاملون بالمستشفى الجهد الكافي لأداء المهام المطلوبة منهم بالقدر \\
\hline
\end{tabular}
المصدر: من إعداد الباحثون من واقع مخرجات برنامج SPSS.

ويتضح من الجدول ارتفاع منتسط الآراء حول العنصرين (يمتلك المستشفى الروئية

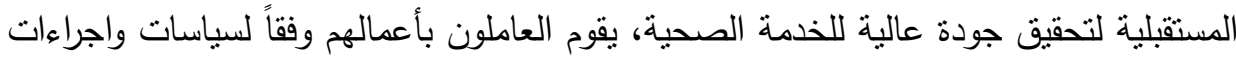
محددة باعتبار ارضاء المريض هو الهذف الرئيسي في المستشفى) بمتوسط (4.58) أي أن بأن

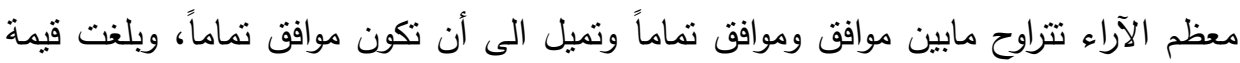

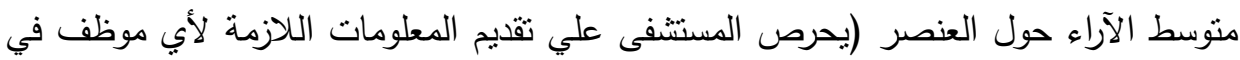

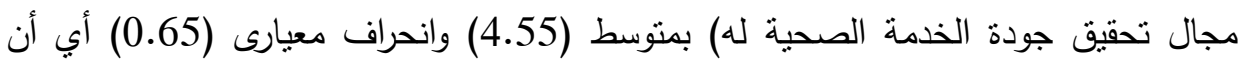

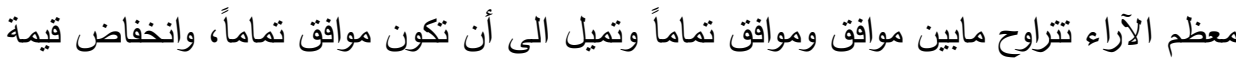

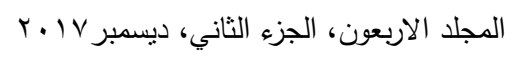


الانحراف المعيارى يذل على أن خفاض التباين فى الآراء او اتفاق عينة الدراسة فيما بينها حول

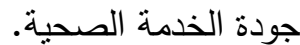

\section{نمتائي القراسمة المهيدانية}

نتائج اختبار الفرض الأول:" لا توجد علاقة ذات دلاله إحصائية بين المراجعة الداخلية

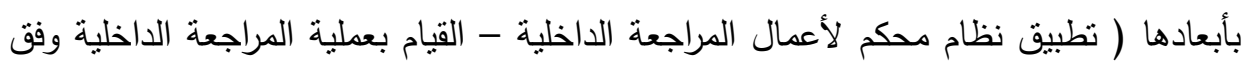

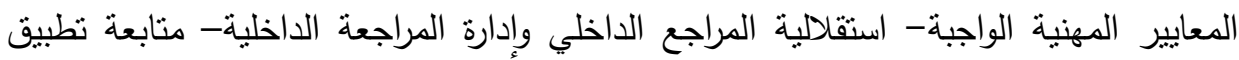
وتقييم نظم وإجراءات المراجعة الداخلية) والأداء البيئي بأبعاده ( دور المراجع الداخلي في مجال الداليه

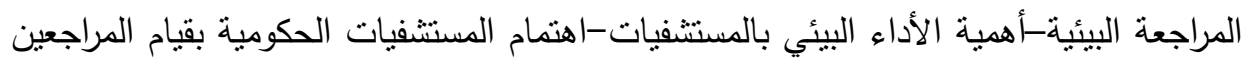

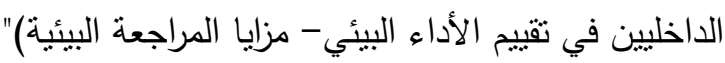
ولاختبار هذا الفرض نم حساب معاملات الارتباط لبيرسون بين المراجعة الداخلية بأبعادها

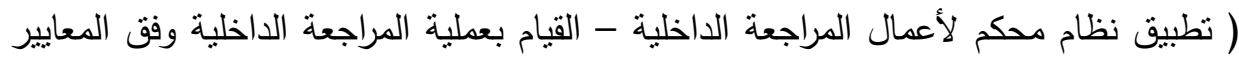
المهنية الواجبة- استقلالية المراجع الداخلي وإدارة المراجعة الداخلية- متابعة تطبيق وتقييم نظم الطمانه

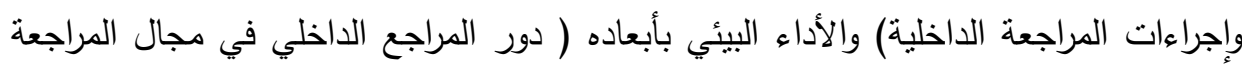
البيئية-أهمية الأداء البيئي بالمستتفيات-اهتمام المستتفيات الحكومية بقيام المراجعين الداخليين

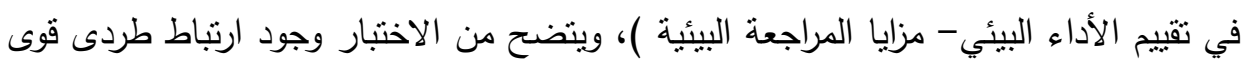

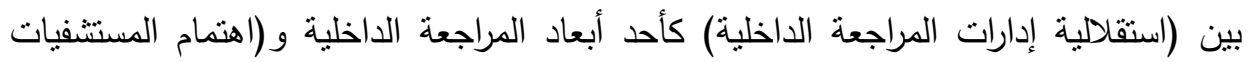

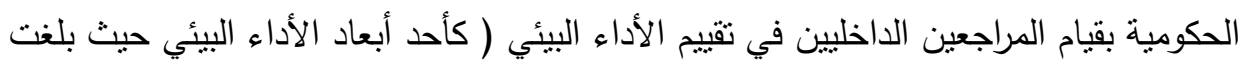

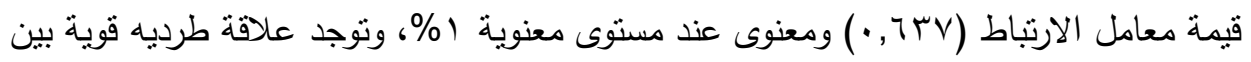

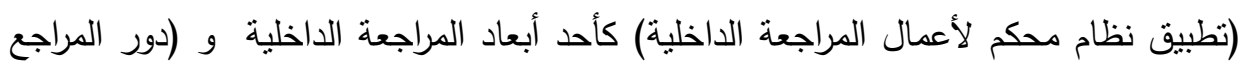

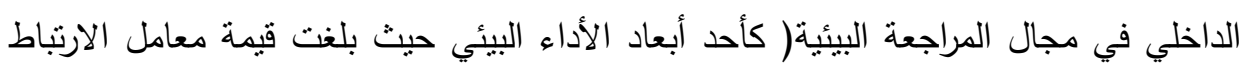

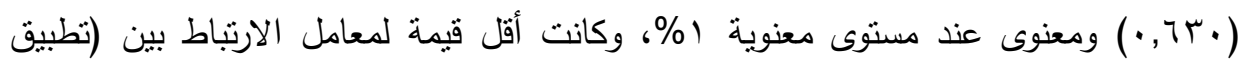
نظام محكم لأعمال المراجعة الداخلية) كأحد أبعاد المراجعة الداخلية و و (أهمية الأداء البيئي 
بالمستشفيات ( كأحد أبعاد الأداء البيئي حيث بلغت قيمة معامل الارتباط (r •r, ·) مما يدل

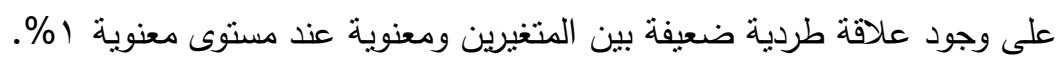
الأمر الذي يعني رفض فرض العدم وقبول الفرض البديل و الذى ينص على فئى ( توجد علاقة ذات دلاله إحصائية بين المراجعة الداخلية بأبعادها والأداء البيئي بأبعاده). اختبار الفرض الثانى: لا توجد علاقة ذات دلاله إحصائية بين المراجعة الداخلية بأبعادها (تطبيق نظام محكم لأعمال المراجعة الداخلية - القيام بعملية المراجعة الداخلية وفق المعايير

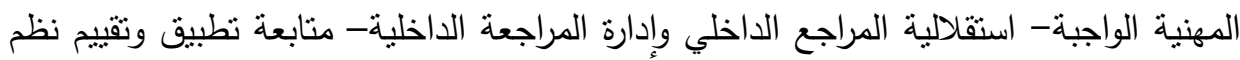
وإجراءات المراجعة الداخلية) وجودة الخدمة الصحية. لاختبار هذا الفرض نم حساب معاملات الارتباط لبيرسون بين المراجعة الداخلية بأبعادها ( تطبيق نظام محكم لأعمال المراجعة الداخلية - القيام بعملية المراجعة الداخلية وفق المعايير المهنية الواجبة- استقلالية المراجع الداخلي وإدارة المراجعة الداخلية- متابعة تطبيق وتقييم نظم وإجراءات المراجعة الداخلية) وجودة الخدمة الصحية، ويتضح من الاختبار وجود ارتباط طردى ولئه

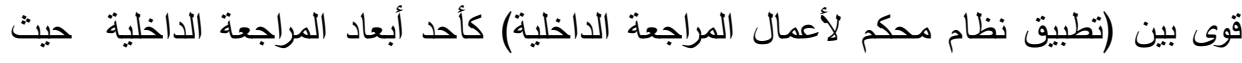

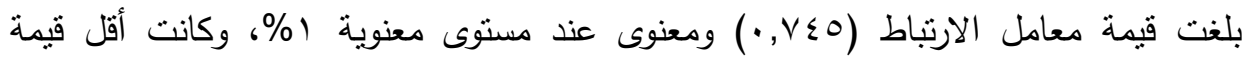

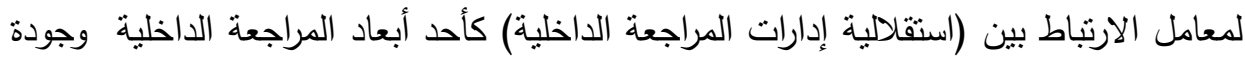

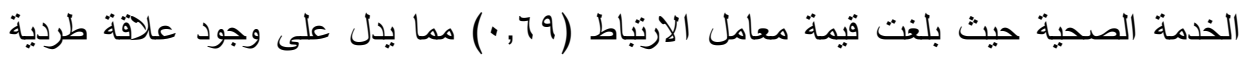

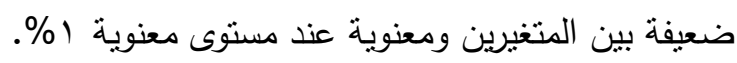

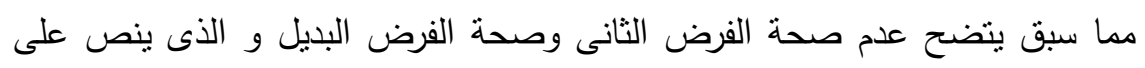
(توجد علاقة ذات دلاله إحصائية بين المراجعة الداخلية بأبعادها وجودة الخدمة الصحية). اختبار الفرض الثالث: "لا توجد علاقة ذات دلاله إحصائية بين الأداء البيئي بأبعاده ( دور

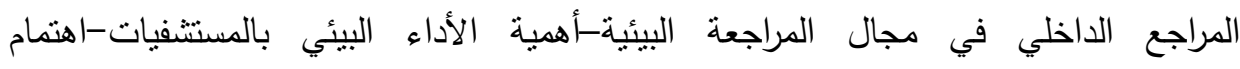
المستشفيات الحكومية بقيام المراجعين الداخليين في تقييم الأداء البيئي- مزايا المراجعة البيئية)وجودة الخدمة الصحية"، لاختبار هذا الفرض تم حساب معاملات الارتباط لبيرسون بين 
الأداء البيئي بأبعاده ( دور المراجع الداخلي في مجال المراجعة البيئية-أهمية الأداء البيئي بالمستتفيات-اهتمام المستشفيات الحكومية بقيام المراجعين الاخليين في تقييم الأداء البيئيمزايا المراجعة البيئية ) وجودة الخدمة الصحية، ويتضح من الاختبار وجود ارتباط طردى قوى لئي

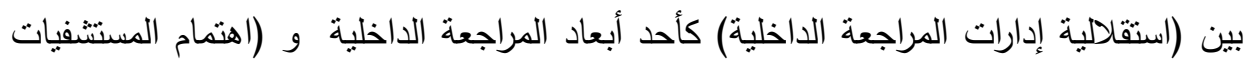

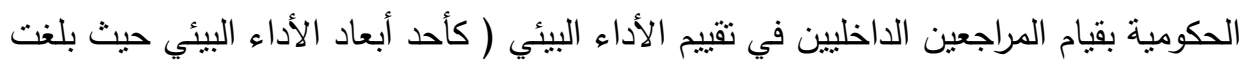

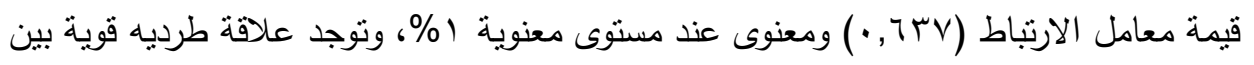

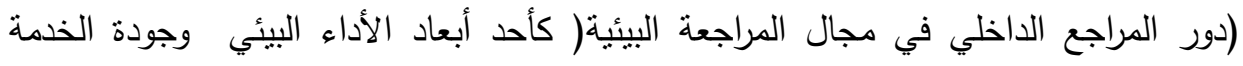

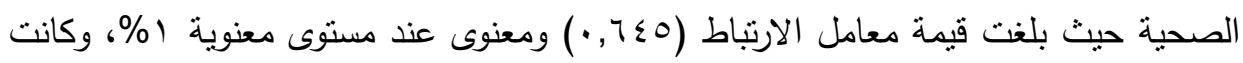
أقل قيمة لمعامل الارتباط بين (اهتمام المستشفيات الحكومية بقيام المراجعين الداخليين في تقييم

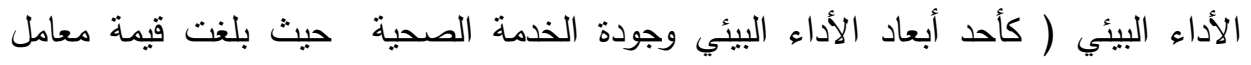
الارتباط (77, ال• ) مما بدل على وجود علاقة طردية ضعيفة بين المتغيرين ومعنوية عند

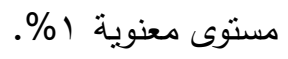
مما سبق يتضح عدم صحة الفرض الثالث وصحة الفرض البديل و الذى ينص على الثى (توجد علاقة ذات دلاله إحصائية بين الأداء البيئي بأبعاده وجودة الخدمة الصحية). اختبار الفرض الرابع: " لا يوجد تأثنر جوهري لأبعاد المراجعة الداخلية على جودة الخدمة

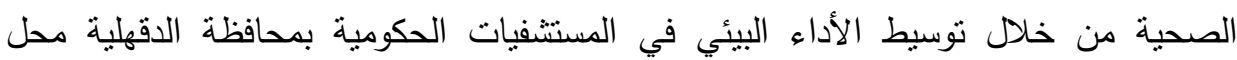

\section{تم اختبار هذا الفرض على مرحلتين كما يلى:} المرحلة الأولى: اختبار وجود تأثير معنوي لأبعاد المراجعة الداخلية على الأداء البيئي: تم

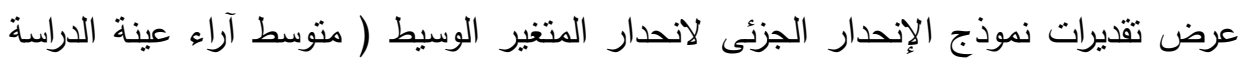

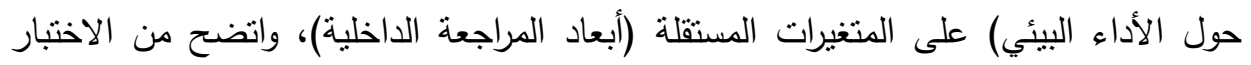

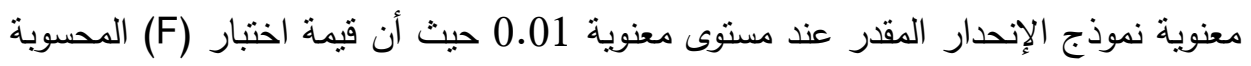
Sig (P- value =0.000) و أقل من مستوى المعنوية، واتضح أيضاً معنوية 
معاملات الانحدار الجزئى ( معاملات المسار) لجميع أبعاد المراجعة الداخلية ماعدا معامل

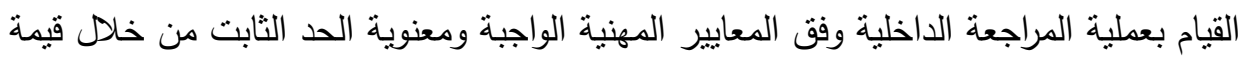
Sig (P- value) t معامل الانحدار الجزئى المعيارى فى النموذج هيى: • • • م استقلالية إدارات المراجعة الداخلية. • متابعة تطبيق وتقييم نظم وإجراءات المراجعة الداخلية.

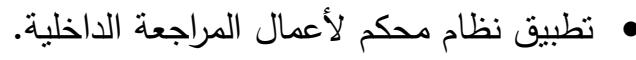

وبلغت قيمة معامل التحديد (0.412) مما يدل على أن أبعاد المراجعة الداخلية كمتغيرات مستقلة تفسر 41.2\% من التغيرات التى تحدث فى فى المتغير التابع (الأداء البيئي) ويتضح مما سبق وجود نأثير معنوى لأبعاد المراجعة الداخلية على الأداء البيئي

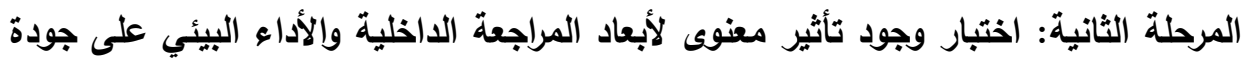

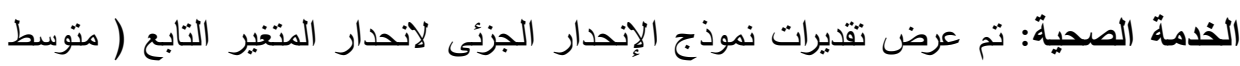
آراء عينة الراسة حول جودة الخدمة الصحية) على المتغيرات المستقلة (أبعاد المراجعة الداخلية والأداء البيئي)، واتضح من الاختبار معنوية نموذج الإنحدار المقدر عند مستوى معنوية 0.01

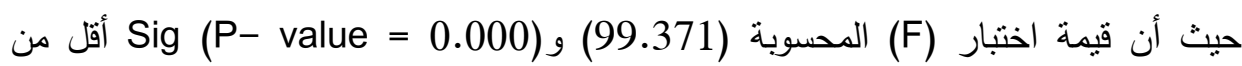
مستوى المعنوية، ويتضح من الجدول معنوية معاملات الاتحدار الجزئى ( معاملات المسار)

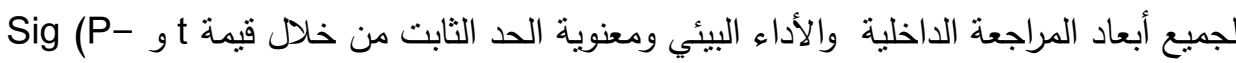
value)

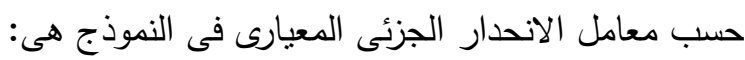
• • تطبيق نظام محكم لأعمال المراجعة الداخلية • متابعة تطبيق وتقييم نظم وإجراءات المراجعة الداخلية.

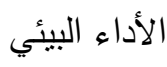

القيام بعملية المراجعة الداخلية وفق المعايير المهنية الواجبة • • م استقلالية إدارات المراجعة الداخلية 
وبلغت قيمة معامل التحديد (0.668) مما يدل على أن أبعاد المراجعة الداخلية والأداء البيئي كمتغيرات مستقلة تقسر 66.8\% من التغيرات التى تحدث فى فى المتغير التابع (جودة الخدمة الصحية) ويتضح مما سبق وجود تأثير معنوى لأبعاد المراجعة الداخلية والأداء البيئي على جودة الخدمة الصحية، ويتضح من المرحلتين زيادة القدرة التفسيرية لأبعاد المراجعة لئهة

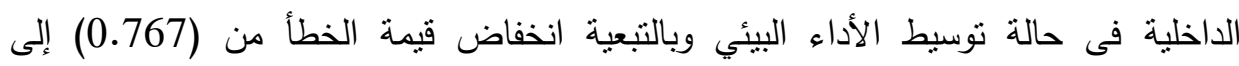

ويتضح مما سبق عدم صحة الفرض الرابع وصحة الفرض البديل و الذى ينص على

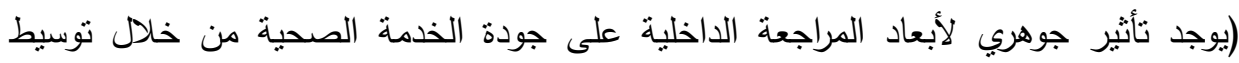
الأداء البيئي في المستتفيات الحكومية بمحافظة الدقهلية محل الدراسة).

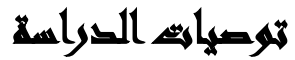

يعرض الباحثون من خلال الجدول رقم (؟) أهم التوصيات التى توصلوا اليها بعرض هول توصيات الدراسة وخطوات التطبيق وجهة التنفيذ: جدول رقم(7): توصيات الدراسة وخطوات التطبيق وجهة التتفيذ.

\begin{tabular}{|c|c|c|c|c|}
\hline الزمني & جهة التتفيذ & خطوات التطبيق & التوصية & م \\
\hline مستمرة. & - & 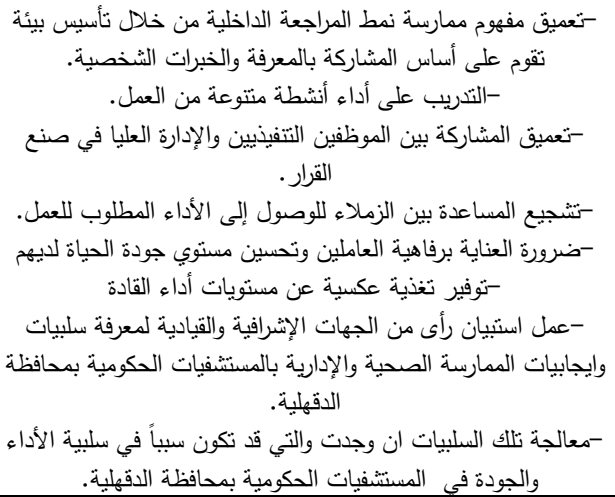 & 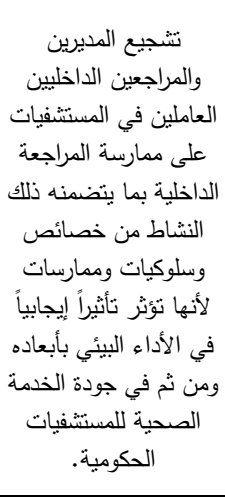 & 1 \\
\hline
\end{tabular}


تابع: جدول رقم(7): توصيات الدراسة وخطوات التطبيق وجهة التتفيذ.

\begin{tabular}{|c|c|c|c|c|}
\hline المدى الزمني & جهة التتفيذ & خطوات التطبيث & التوصية & م \\
\hline بصفة مستمرة. & 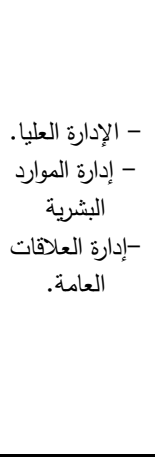 & 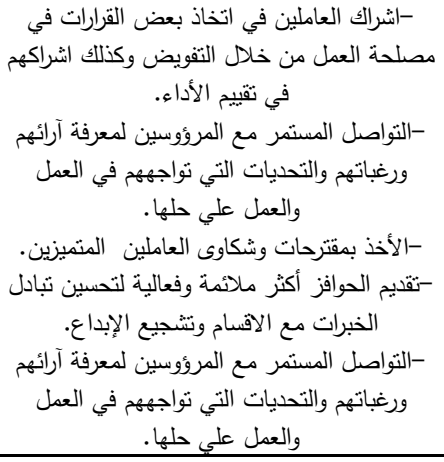 & 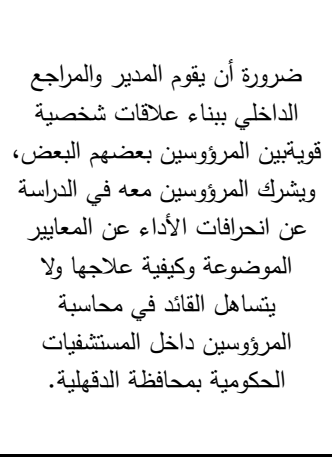 & r \\
\hline بصفة مستمرة & 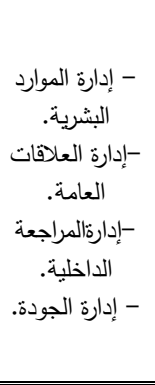 & 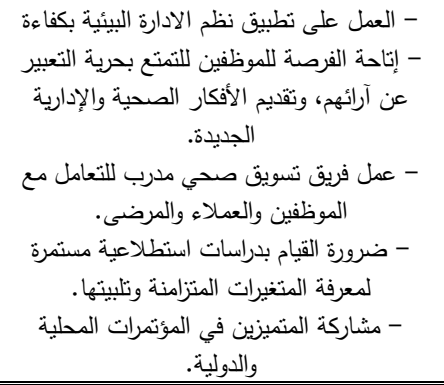 & 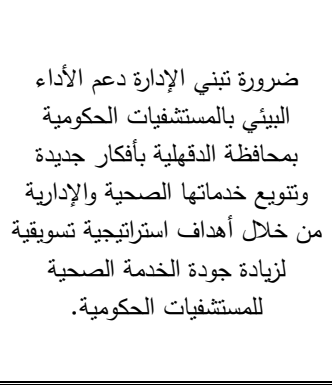 & $r$ \\
\hline بصفة مستمرة & 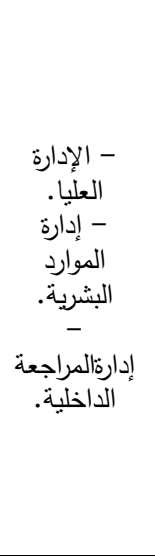 & 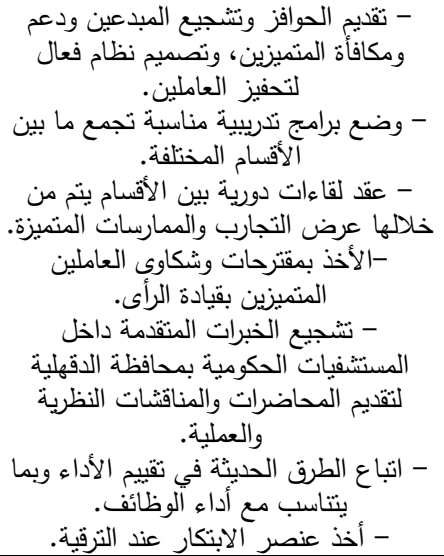 & 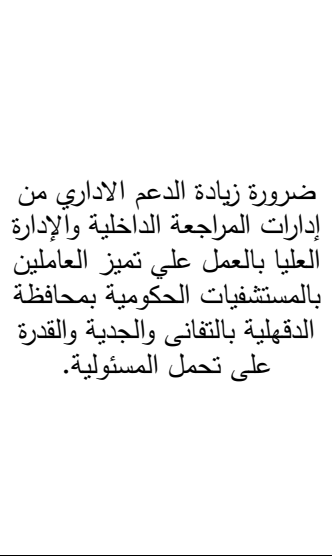 & $\varepsilon$ \\
\hline
\end{tabular}


تابع: جدول رقم(؟): توصيات الدراسة وخطوات التطبيق وجهة التنفيذ.

\begin{tabular}{|c|c|c|c|c|}
\hline المدى الزمني & جهة التتفيذ & خطوات التطبيق & التوصية & b \\
\hline بصفة مستمرة & - العإليا. البشارة - البرارة & 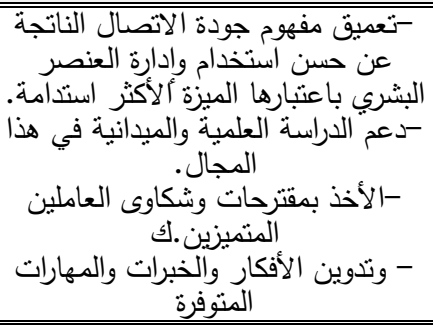 & 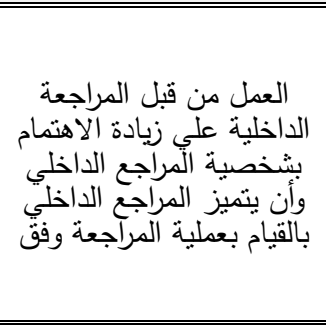 & 0 \\
\hline & & 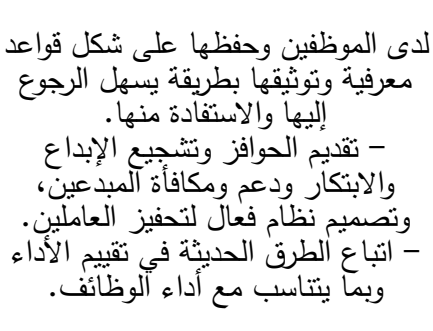 & 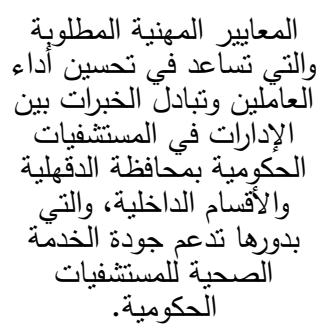 & \\
\hline
\end{tabular}

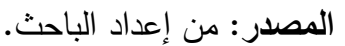

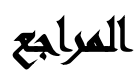

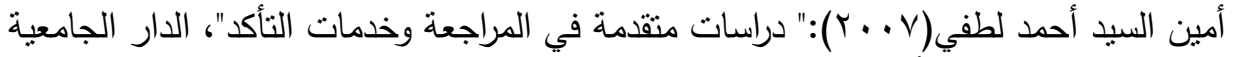

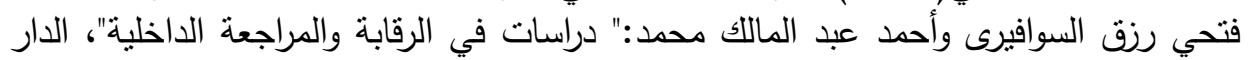

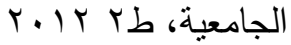

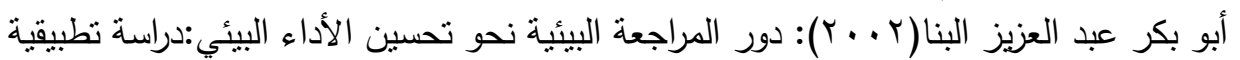

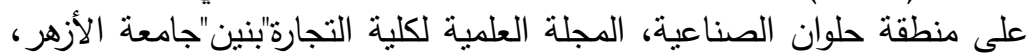

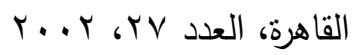

إيناس محمد نبوي: "إنتاج الإسمنت في مصر وأناره البيئية المجلة العلمية للافتصاد والتجارة،

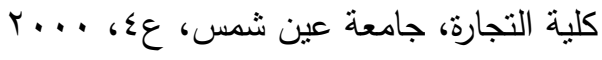




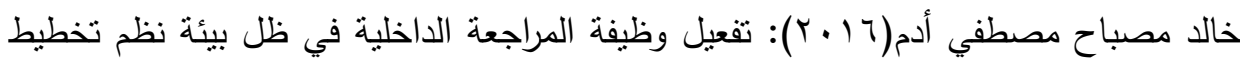
موارد المنظمة ERP، رسالة ماجستير غير منشورة ، كلية التجارة ، جامعة فئة فئة

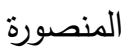

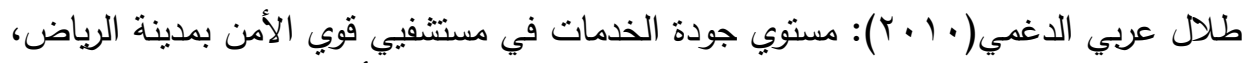

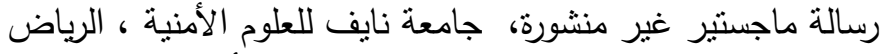

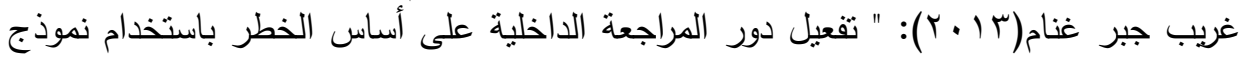
تحليل آثار الإخفاق "، المجلة العلمية التجارة والتمويل، كلية التجارة - جامعة التحاتة

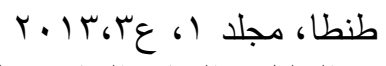

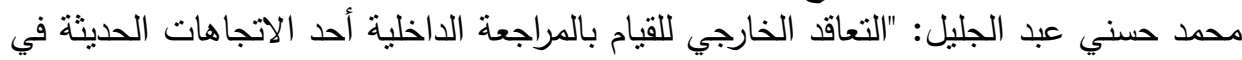

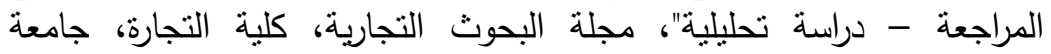

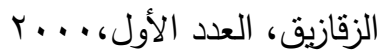

محمد عبد اله محمد عبد الهه: "استخدام تحليل المسار في قياس أثر متغيرات الهيكل التنظيمي

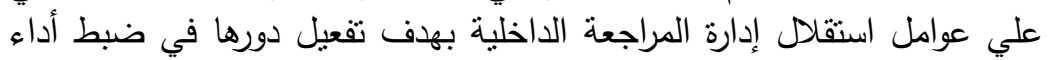
الشركات - دراسة تطبيقية"، مجلة الدراسات والبحوث التجارية التهارية، كلية التجارة،

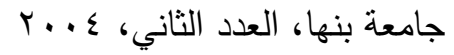

Berhane, A. and Enquselassie, F., (2015), "Patients' preferences for attributes related to health care services at hospitals in Amhara Region, northern Ethiopia: a discrete choice experiment", Dove Press Journal, Patient Preference and Adherence 2015:9, 1293-130.

Ebrahim Jaafari pooyan Dila Agrizzi; Faizollah Akbari-Haghighi ;(2011), "Healthcare Accreditation System Further Perspectives on Performance Measures" Posted: 11/28/2011; International Journal for Quality in Health Care. 2011; 23(6):645-656. Oxford University.

Lumberton, Jeff ;(2012), "The Internal auditor to Participate in the Environmental Audit, Evidence From Thailand", ic \& ai The Audit in daily Practice, Vol. 4.

Musunurn, K., (2012), "Patients' choice or switching attitude towards healthcare services in private hospitals", International Journal of Engineering and Management sciences, Vol.2, No.4.

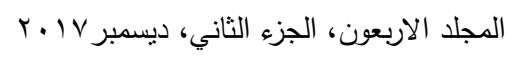


Sritharan, V., (2014), "Measuring Service Quality Dimensions: an Empirical study of private Hospitals in Jaffna District, Sri Lanka", Journal of Marketing and Consumer Research, Vol.3.

\title{
A PROPOSED FRAMEWORK TO DEVELOP THE ROLE OF INTERNAL AUDITING AS AN APPROACH TO ENHANCE THE QUALITY OF HEALTH SERVICE AND ENVIRONMENTAL PERFORMANCE IN GOVERNMENTAL HOSPITAL
}

\section{A FIELD STUDY}

Mohamed, M. A. ${ }^{(1)}$; Mohamed, M. A. ${ }^{(2)}$ and Kazamel, A. A.

1) Faculty of Commerce, Ain Shams University 2) Faculty of medicine, El-mansoura University

\begin{abstract}
The study aimed to develop a proposed framework for developing the role of the internal auditor in improving the quality of health service and environmental performance (in light of the promulgation of Law No. 4 of 1994 and amended by Law No. 9 of 2009 on the rules, procedures and controls to be followed to reduce pollution of the environment) The role of the internal auditor in evaluating the quality of service and the extent of compliance with environmental requirements and legislation in light of the recent trends in the standards of professional performance. The researchers adopted the theoretical and applied methods, The study used the SPSS program to test the study hypotheses and analyze the results. The study found that there is a strong correlation between the
\end{abstract}


internal audit (Implementing an internal audit system - conducting internal audit in accordance with the applicable professional standards independence of the internal audit department - following up the application and evaluation of internal audit systems and procedures) and the internal performance The importance of environmental performance in hospitals - the interest of government hospitals in assessing environmental performance - quality of health service). The study recommended that the work of the internal audit should increase attention to the personality of the internal auditor and that the internal auditor should perform the review according to the required professional standards, Improve employee performance. 